\title{
Next-generation ARIA care pathways for rhinitis and asthma: a model for multimorbid chronic diseases
}

\begin{abstract}
J. Jean Bousquet ${ }^{1,2,3,4^{*}}$ (D) , Holger J. Schünemann ${ }^{6}$, Alkis Togias' ${ }^{7}$, Marina Erhola ${ }^{8}$, Peter W. Hellings ${ }^{3,9,10}$,

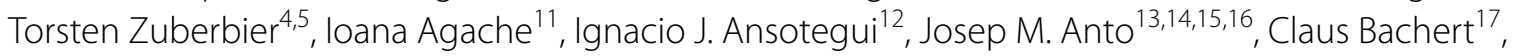
Sven Becker ${ }^{18}$, Martin Bedolla-Barajas ${ }^{19}$, Michael Bewick ${ }^{20}$, Sinthia Bosnic-Anticevich ${ }^{21,22,23}$, Isabelle Bosse ${ }^{24}$, Louis P. Boulet ${ }^{25}$, Jean Marc Bourrez ${ }^{26}$, Guy Brusselle ${ }^{27}$, Niels Chavannes ${ }^{28}$, Elisio Costa ${ }^{29}$, Alvaro A. Cruz ${ }^{30,31}$, Wienczyslawa Czarlewski ${ }^{32}$, Wytske J. Fokkens ${ }^{3,33}$, Joao A. Fonseca ${ }^{34,35}$, Mina Gaga ${ }^{36}$, Tari Haahtela ${ }^{37}$, Maddalena Illario ${ }^{38}$, Ludger Klimek ${ }^{39}$, Piotr Kuna ${ }^{40}$, Violeta Kvedariene ${ }^{41}$, L. T. T. Le ${ }^{42}$,

Desiree Larenas-Linnemann ${ }^{43}$, Daniel Laune ${ }^{44}$, Olga M. Lourenço ${ }^{45}$, Enrica Menditto ${ }^{46}$, Joaquin Mullol ${ }^{47,48}$, Yashitaka Okamoto ${ }^{49}$, Nikos Papadopoulos ${ }^{50,51}$, Nhân Pham-Thi ${ }^{52}$, Robert Picard ${ }^{53}$, Hilary Pinnock ${ }^{54}$, Nicolas Roche ${ }^{55}$, Regina E. Roller-Wirnsberger ${ }^{56}$, Christine Rolland ${ }^{57}$, Boleslaw Samolinski ${ }^{58}$, Aziz Sheikh ${ }^{54}$, Sanna Toppila-Salmi ${ }^{37}$, Ioanna Tsiligianni ${ }^{59,60}$, Arunas Valiulis ${ }^{61}$, Erkka Valovirta ${ }^{62}$, Tuula Vasankari63, Maria-Teresa Ventura ${ }^{64}$, Samantha Walker ${ }^{65}$, Sian Williams ${ }^{62}$, Cezmi A. Akdis ${ }^{66}$, Isabella Annesi-Maesano ${ }^{67}$, Sylvie Arnavielhe ${ }^{44}$, Xavier Basagana ${ }^{13,14,15,16}$, Eric Bateman ${ }^{68}$, Anna Bedbrook', K. S. Bennoor ${ }^{69}$,
\end{abstract} Samuel Benveniste ${ }^{70}$, Karl C. Bergmann ${ }^{4,5}$, Slawomir Bialek ${ }^{71}$, Nils Billo ${ }^{72}$, Carsten Bindslev-Jensen ${ }^{73,74}$, Leif Bjermer ${ }^{75}$, Hubert Blain ${ }^{76,77}$, Mateo Bonini ${ }^{78,79}$, Philippe Bonniaud ${ }^{80}$, Jacques Bouchard ${ }^{81,82}$, Vitalis Briedis ${ }^{83}$, Christofer E. Brightling ${ }^{84,85}$, Jan Brozek ${ }^{6}$, Roland Buhl ${ }^{86}$, Roland Buonaiuto ${ }^{87}$, Giorgo W. Canonica ${ }^{88}$, Victoria Cardona ${ }^{89}$, Ana M. Carriazo ${ }^{90}$, Warner Carr ${ }^{91}$, Christine Cartier $^{92}$, Thomas Casale ${ }^{93}$, Lorenzo Cecchi ${ }^{94}$, Alfonso M. Cepeda Sarabia ${ }^{95,96}$, Eka Chkhartishvili97, Derek K. Chu ${ }^{3}$, Cemal Cingi ${ }^{98}$, Elaine Colgan ${ }^{99}$, Jaime Correia de Sousa ${ }^{100,101}$, Anne Lise Courbis ${ }^{102}$, Adnan Custovic ${ }^{103}$, Biljana Cvetkosvki²1,22,23, Gennaro D'Amato ${ }^{104}$, Jane da Silva ${ }^{105}$, Carina Dantas ${ }^{106,107}$, Dejand Dokic ${ }^{108}$, Yves Dauvilliers ${ }^{109}$, Antoni Dedeu110,111, Giulia De Feo ${ }^{112}$, Philippe Devillier ${ }^{113}$, Stefania Di Capua ${ }^{114}$, Marc Dykewickz ${ }^{115}$, Ruta Dubakiene ${ }^{116}$, Motohiro Ebisawa ${ }^{117}$, Yaya El-Gamal ${ }^{118}$, Esben Eller ${ }^{73,74}$, Regina Emuzyte ${ }^{119}$, John Farrell ${ }^{101}$, Antjie Fink-Wagner ${ }^{120}$, Alessandro Fiocchi ${ }^{121}$, Jean F. Fontaine ${ }^{122}$, Bilun Gemicioğlu ${ }^{123}$,

Peter Schmid-Grendelmeir ${ }^{124}$, Amiran Gamkrelidze ${ }^{125}$, Judith Garcia-Aymerich ${ }^{13}$, Maximiliano Gomez ${ }^{126}$,

Sandra González Diaz ${ }^{127}$, Maia Gotua ${ }^{128}$, Nick A. Guldemond ${ }^{129}$, Maria-Antonieta Guzmán ${ }^{130}$, Jawad Hajjam ${ }^{131}$, John O'B Hourihane ${ }^{132}$, Marc Humbert ${ }^{133}$, Guido laccarino ${ }^{134}$, Despo lerodiakonou ${ }^{59,62}$, Maddalena Illario ${ }^{35}$, Juan C. Ivancevich ${ }^{135}$, Guy Joos ${ }^{25}$, Ki-Suck Jung ${ }^{136}$, Marek Jutel ${ }^{137}$, Igor Kaidashev ${ }^{138}$, Omer Kalayci ${ }^{139}$, Przemyslaw Kardas ${ }^{140}$, Thomas Keil ${ }^{141,142}$, Mussa Khaitov ${ }^{143}$, Nikolai Khaltaev ${ }^{144}$, Jorg Kleine-Tebbe ${ }^{145}$, Marek L. Kowalski ${ }^{146}$, Vicky Kritikos ${ }^{21,22,23}$, Inger Kull ${ }^{147,148}$, Lisa Leonardini ${ }^{149}$, Philip Lieberman ${ }^{150}$, Brian Lipworth ${ }^{151}$, Karin C. Lodrup Carlsen ${ }^{152,153}$, Claudia C. Loureiro ${ }^{154}$, Renaud Louis ${ }^{155}$, Alpana Mair ${ }^{156}$, Gert Marien³, Bassam Mahboub ${ }^{157}$, Joao Malva ${ }^{107,158}$, Patrick Manning ${ }^{159}$, Esteban De Manuel Keenoy ${ }^{160}$,

\footnotetext{
*Correspondence: jean.bousquet@orange.fr

${ }^{1}$ MACVIA-France, Fondation Partenariale FMC VIA-LR, CHU,

34295 Montpellier Cedex 5, France

Full list of author information is available at the end of the article
} 
Gailen D. Marshall ${ }^{161}$, Mohamed R. Masjedi ${ }^{162}$, Jorge F. Maspero ${ }^{163}$, Eve Mathieu-Dupas ${ }^{44}$, Poalo M. Matricardi ${ }^{164}$, Eric Melén ${ }^{148,165}$, Elisabete Melo-Gomes ${ }^{166}$, Eli O. Meltzer ${ }^{167}$, Enrica Menditto ${ }^{46}$, Jacques Mercier ${ }^{168}$, Neven Miculinic ${ }^{169}$, Florin Mihaltan ${ }^{170}$, Branislava Milenkovic ${ }^{171}$, Giuliana Moda ${ }^{172}$, Maria-Dolores Mogica-Martinez ${ }^{173}$, Yousser Mohammad ${ }^{174,175}$, Steve Montefort ${ }^{176}$, Ricardo Monti ${ }^{177}$, Mario Morais-Almeida ${ }^{178}$, Ralf Mösges ${ }^{179,180}$, Lars Münter ${ }^{181}$, Antonella Muraro ${ }^{182}$, Ruth Murray ${ }^{183,184}$, Robert Naclerio ${ }^{185}$, Luigi Napoli ${ }^{186}$, Leila Namazova-Baranova ${ }^{187}$, Hugo Neffen ${ }^{188,189}$, Kristoff Nekam ${ }^{190}$, Angelo Neou ${ }^{191}$, Enrico Novellino ${ }^{192}$, Dieudonné Nyembue ${ }^{193}$, Robin O'Hehir ${ }^{194}$, Ken Ohta ${ }^{261}$, Kimi Okubo ${ }^{195}$, Gabrielle Onorato', Solange Ouedraogo ${ }^{196}$, Isabella Pali-Schöll197, Susanna Palkonen ${ }^{198}$, Peter Panzner ${ }^{199}$, Hae-Sim Park 200, Jean-Louis Pépin 201,202, Ana-Maria Pereira 203,204, Oliver Pfaar ${ }^{206}$, Ema Paulino 207, Jim Phillips ${ }^{208,}$ Robert Picard ${ }^{53}$, Davor Plavec ${ }^{209,210}$, Ted A. Popov ${ }^{211}$, Fabienne Portejoie', David Price ${ }^{212,213,}$ Emmanuel P. Prokopakis ${ }^{214}$, Benoit Pugin ${ }^{3}$, Filip Raciborski ${ }^{58}$, Rojin Rajabian-Söderlund ${ }^{215}$, Sietze Reitsma ${ }^{3,33}$, Xavier Rodo ${ }^{13}$, Antonino Romano 216,217, Nelson Rosario ${ }^{218}$, Menahenm Rottem ${ }^{219}$, Dermot Ryan ${ }^{220}$, Johanna Salimäki ${ }^{221}$, Mario M. Sanchez-Borges ${ }^{222}$, Juan-Carlos Sisul ${ }^{223}$, Dirceu Solé224, David Somekh ${ }^{225}$, Talant Sooronbaev ${ }^{226}$, Milan Sova ${ }^{227}$, Otto Spranger ${ }^{120}$, Cristina Stellato ${ }^{112}$, Rafael Stelmach ${ }^{228}$, Charlotte Suppli Ulrik ${ }^{229}$, Michel Thibaudon ${ }^{230}$, Teresa To ${ }^{231}$, Ana Todo-Bom ${ }^{154}$, Peter V. Tomazic ${ }^{232}$ Antonio A. Valero ${ }^{233}$, Rudolph Valenta ${ }^{234,235,236}$, Marylin Valentin-Rostan ${ }^{237}$, Rianne van der Kleij ${ }^{238,239}$, Olivier Vandenplas ${ }^{240}$, Giorgio Vezzani ${ }^{241}$, Frédéric Viart ${ }^{92}$, Giovanni Viegi ${ }^{242,243}$, Dana Wallace ${ }^{244}$, Martin Wagenmann245, De Y. Wang ${ }^{246}$, Susan Waserman ${ }^{247}$, Magnus Wickman ${ }^{248}$, Dennis M. Williams ${ }^{249}$ Gary Wong ${ }^{205}$, Piotr Wroczynski ${ }^{71}$, Panayiotis K. Yiallouros ${ }^{250,251}$, Arzu Yorgancioglu252, Osman M. Yusuf ${ }^{253}$, Heahter J. Zar ${ }^{254,255}$, Stéphane Zeng ${ }^{256}$, Mario Zernotti ${ }^{257}$, Luo Zhang ${ }^{258}$, Nan S. Zhong ${ }^{259}$, Mihaela Zidarn ${ }^{260}$, the ARIA Study Group and the MASK Study Group

\section{Abstract}

Background: In all societies, the burden and cost of allergic and chronic respiratory diseases are increasing rapidly. Most economies are struggling to deliver modern health care effectively. There is a need to support the transformation of the health care system into integrated care with organizational health literacy.

Main body: As an example for chronic disease care, MASK (Mobile Airways Sentinel Network), a new project of the ARIA (Allergic Rhinitis and its Impact on Asthma) initiative, and POLLAR (Impact of Air POLLution on Asthma and Rhinitis, EIT Health), in collaboration with professional and patient organizations in the field of allergy and airway diseases, are proposing real-life ICPs centred around the patient with rhinitis, and using mHealth to monitor environmental exposure. Three aspects of care pathways are being developed: (i) Patient participation, health literacy and self-care through technology-assisted "patient activation", (ii) Implementation of care pathways by pharmacists and (iii) Nextgeneration guidelines assessing the recommendations of GRADE guidelines in rhinitis and asthma using real-world evidence (RWE) obtained through mobile technology. The EU and global political agendas are of great importance in supporting the digital transformation of health and care, and MASK has been recognized by DG Santé as a Good Practice in the field of digitally-enabled, integrated, person-centred care.

Conclusion: In 20 years, ARIA has considerably evolved from the first multimorbidity guideline in respiratory diseases to the digital transformation of health and care with a strong political involvement.

Keywords: Health care transformation, Care pathways, Rhinitis, ARIA, MASK, POLLAR

\section{Background}

In all societies, the burden and cost of non-communicable diseases (NCDs) are increasing rapidly as advances in sanitation, public health measures and clinical care result in changes in demography [1]. Most, if not all, economies are struggling to deliver modern health care effectively
[2]. Budgets will continue to be challenged with the move towards universal health coverage as demand increases and newer, more expensive technologies become available [3-5]. Traditional programmes, heavily reliant on specialist and supporting services, are becoming unaffordable. Innovative solutions are required to alleviate 
system wide pressures [6, 7]. There is a need to support authorities in the transformation of the health care system into integrated care with organizational health literacy [8].

Integrated care pathways (ICPs) are structured multidisciplinary care plans detailing the key steps of patient care [9]. They promote the translation of guideline recommendations into local protocols and their application to clinical practice. They may be of particular interest in patients with multimorbidities since guidelines rarely consider them appropriately $[10,11]$. An ICP forms all or part of the clinical record, documents the care given, and facilitates the evaluation of outcomes for continuous quality improvement [12]. ICPs should be carried out by a multidisciplinary team including physicians, pharmacists $[13,14]$ and allied health care professionals [15]. ICPs should integrate recommendations from clinical practice guidelines, but they usually (i) enhance recommendations by combining interventions, integrating quality assurance and (ii) describe co-ordination of care. Self-care and shared decision making are at the forefront of ICPs with the aim of empowering patients and their (professional and lay) care givers.

Rhinitis and asthma multimorbidity can be used as a model for chronic diseases since there is a broad agreement on the 'gold standard' of care [16-18]. In allergic rhinitis (AR) and asthma, adherence to treatment is a major unresolved problem $[19,20]$. The vast majority of physicians prescribe regular treatment but patients (and physicians when they are allergic [21]) do not adhere to the advice. Instead of they self-treat based on personal experience as suggested by real-world data $[19,22]$. There is thus a major disconnect between physicians and patients, either because of the clinical approach utilised or due to a lack of patient health literacy, with insufficient shared decision making (SDM). On-demand (prn) approaches are now proposed in both diseases [23-25] and represent a major change from previous recommendations. This new approach should be integrated in ICPs, but it needs to be applied to self-management and based on solid evidence.

ICPs have been proposed with a focus on new technologies that, through personally-held data on tablet devices and recording of 'symptom load', should enhance self-management and adherence to guidelines and ICPs. The science of supporting self-care and ICPs through mobile devices (mHealth) is in its infancy, but preliminary results are encouraging [26-28]. In the context of asthma, a systematic review showed that mobile apps were generally as effective as traditional models of supported self-management, but that they may be preferred in some clinical and demographic contexts as being convenient as well as efficient for the patient and the professional [29]. Standardisation and the establishment of the
Privacy Code of Conduct for mHealth apps [25] will be important in ensuring patients on the safeguard of their data and in helping them choose reliable technological tools, which will be essential for ICP implementation.

As an example for chronic disease care, a new development of the ARIA initiative (ARIA phase 4) [30], along with POLLAR (Impact of Air POLLution on Asthma and Rhinitis), in collaboration with professional and patient organizations in the field of allergy and airway diseases, are proposing real-life ICPs centred around the patient with rhinitis, and using mHealth to monitor environmental exposure.

The current document was finalized and reviewed during a meeting involving ARIA, POLLAR (Impact of Air POLLution on Asthma and Rhinitis (EIT Health)), the European Innovation Partnership on Active and Healthy Ageing and the Global Alliance against Chronic Respiratory Diseases (GARD, WHO Alliance). Major allergy societies and patient's organizations participated in this meeting (Paris, December 3, 2018). The event was carried out with the support of many organizations (Fig. 1).

\section{The gaps in allergic rhinitis and asthma}

$\mathrm{AR}$ is the most common chronic disease worldwide. Treatment guidelines have improved the knowledge on rhinitis and have had a significant impact on AR management. However, many patients still fail to achieve sufficient symptom control [31] and the costs for society are enormous, in particular due to a major impact on school and work productivity [32] and on allergic or non-allergic multimorbidities [33, 34]. Allergic Rhinitis and its Impact on Asthma (ARIA) has promoted the use of its recommendations $[16,35,36]$ to be integrated in ICPs using mobile technology in AR and asthma multimorbidity across the life cycle [37].

The clinical problem is that a large number of AR patients do not consult physicians because they think their symptoms are 'normal' and/or trivial, even though AR negatively impacts social life, school and work productivity [36]. Many AR patients rely on over-the-counter (OTC) drugs and do not see the need to consult with physicians [38-41]. The vast majority of patients who visit general practitioners (GPs) or specialists have moderate-to-severe rhinitis [42-46]. ICPs should take this reality into account and consider a multi-disciplinary approach as proposed by AIRWAYS ICPs (Fig. 2).

\section{Supported self-management}

People with AR and asthma are, by default, making dayto-day decisions about the management of their condition (avoiding triggers, using various treatments and seeking professional advice). Reflecting this broad concept, selfmanagement is defined as "the tasks that individuals must 

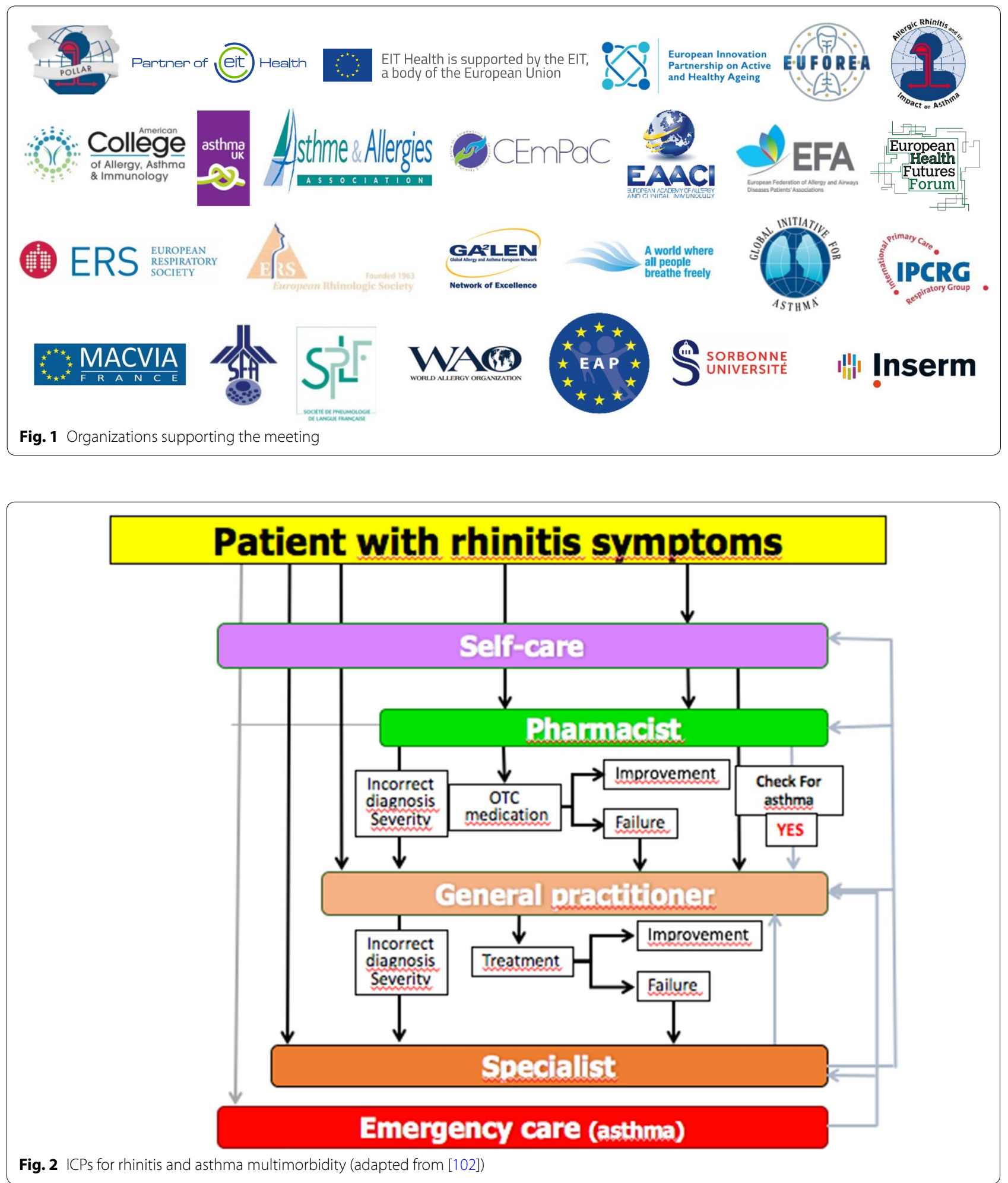

undertake to live well with one or more chronic conditions. These tasks include having the confidence to deal with the medical management, role management and emotional management of their conditions" [47].
The term self-care includes generic "healthy lifestyle behaviours required for human development and functioning" [48]. However, self-care and self-management overlap as, for example, smoking cessation is a generic 
self-care behaviour and a component of self-management for people with respiratory conditions.

Self-management support is the assistance that professionals (pharmacy, primary care, specialist), patient's organizations and other sources of information, as well as informal caregivers, give patients in order to make decisions about their condition and to manage disease and health-related tasks [49]. A taxonomy of 14 components of self-management support [50] offers a pick-list of activities that may be considered when planning selfmanagement. These could be practical activities (e.g. teaching inhaler technique, discussing an action plan, helping to quit smoking) and imply SDM [50]. Mobile technology has the potential to contribute to many aspects of the supported self-management of chronic diseases [51].

Supported self-management is a 'key principle' for ICPs in long-term conditions [52, 53]. This not only reflects the paradigm shift towards SDM, but also includes pragmatic, economic imperatives, as healthcare systems respond to the increasing NCD burden. The economic impact of effective supported self-management goes beyond healthcare savings. For example, major economic return can be in the workplace where absenteeism and, more importantly, presenteeism are reduced [32] leading to an increased productivity.

Patient activation, defined as the "knowledge, skills and confidence a person has in managing his/her own health and health care" [54], is a goal of many ICP models. "Activation" encompasses the patients' beliefs about their ability to self-manage (self-efficacy) and the likelihood that they will put these beliefs into action. Levels of activation range from the disengaged patients who let others manage their condition to the fully "activated" patients who embrace SDM and manage their health in partnership with their healthcare advisors, understanding the escalation of treatment options and when to seek pharmacy or medical advice. Higher levels of activation have been associated with better process and health outcomes in adults [55] and there is some evidence that appropriatelytargeted self-management support may be more beneficial to disadvantaged groups than to higher literacy/ socioeconomic status patients.

Although ARIA appears to meet the patient's needs, real-life data obtained using the Allergy Diary (MASKair $^{\circledR}$ ) app from around 10,000 people in 23 countries (Argentina, Austria, Australia, Belgium, Brazil, Canada, Czech Republic, Denmark, Finland, France, Germany, Greece, Italy, Lithuania, Mexico, Netherlands, Poland, Portugal, Spain, Sweden, Switzerland, UK. Brazil is a developing country) have shown that very few patients are being treated according to guidelines and that they often self-medicate [19]. Self-medication is the treatment of common health problems with medicines without medical supervision. It is important to ensure that well-written, short and accurate self-management information is available for people to pick up in pharmacies, or for download. In the case of AR, many patients have prescribed medications at home and, when symptoms occur, they use them. Self-care and SDM centred around the patient should be used more often [56]. ARIA has already followed a change management $(\mathrm{CM})$ strategy embedding the AR-asthma multimorbidity in every day practice [30], but a new $\mathrm{CM}$ is now being considered to increase the benefits of self-care and SDM in ICPs using currently-available IT tools. In the case of AR and asthma multimorbidity, aeroallergen exposure and pollution impact disease control and medications. However, there is currently no ICP in airway diseases that takes such environmental parameters into account [57]. These initiatives should prepare and support individuals, teams and organizations in making organizational change centred around the patient.

mHealth, such as apps running on consumer smart devices, is becoming increasingly popular and has the potential to profoundly affect health care and health outcomes [58]. Several apps exist for AR and asthma [5963]. A review of the Apps in the field of allergic diseases has recently been completed (Matricardi et al. in preparation). One of the reviews-MASK (Mobile Airways Sentinel NetworK), the Phase 3 ARIA initiative [37, 64]is based on the freely-available MASK app (the Allergy Diary, Android and iOS platforms) for AR and asthma. Importantly, MASK is available in 17 languages and deployed in 23 countries [64]. Data from 26,000 users reporting over 200,000 days of treatment are available. It complies with the recent General Data Protection Regulation (EU) 2016/679 (GDPR) enforced by the EU, May 25, 2018 [65]. The GDPR aims primarily to give control to citizens and residents over their personal data and to simplify the regulatory environment by unifying the regulation within the EU $[66,67]$. Importantly, MASK enables the assessment of treatment patterns in real life and provides detailed information on treatment, given that the Allergy Diary is able to distinguish between AR medications [19].

\section{On-line information}

Most patients check on-line to help them decide what the problem is and how to address it. This is a crucial selfmanagement area of support and we need to think about how it can be optimized. Because of the multiplicity of sources and the lack of reliability control, it should be recognized that such a task would require an enormous effort. Consequently, it has been abandoned by many 
other bodies/disease areas. One approach that may be of value in improving reliability would be to focus on sites that provide useful information and generate an accreditation process with international standing.

\section{Pharmacist care}

Pharmacists are trusted health care professionals. Most patients with rhinitis are seen by pharmacists who are the initial point of contact of AR management in most countries. Depending on the country, few or most AR medications are available over-the-counter (OTC) [68-71] and are used by many patients. Therefore, as trusted health care professionals in the community, pharmacists are well placed to play a critical role identifying the symptoms of AR, recommending appropriate OTC treatment [38, 39, $41]$ and integrating health care teams through ICPs [13, 14]. The specific role of pharmacists in the management of AR within ICPs can been evidenced from several strategies that have been initiated [72] or completed and from studies confirming the important impact of pharmacist interventions on AR outcomes [40, 70, 73-80].

ARIA in the pharmacy 2004 [38] is being revised in order to propose ICPs involving a multi-disciplinary approach. This paper has been built on the evidence and provides tools intended to help pharmacists give optimal advice/interventions/strategies to patients with rhinitis. The ARIA-pharmacy ICP includes a diagnostic questionnaire specifically focusing attention on key symptoms and markers of the disease, a systematic Diagnosis Guide (including a differential diagnosis) and a simple flowchart proposing treatment for rhinitis and asthma multimorbidity. Key prompts for referral within the ICP are included. The use of technology is critical for enhancing the management of AR. The ARIA-pharmacy ICP should be adapted to local health care environments/situations as large regional or national differences in pharmacybased care exist.

\section{Next-generation guidelines}

Practice guidelines contain evidence-based statements about treatment, tests, public health actions and policy decisions intended to assist recipients of care and their care providers in making informed decisions.

ARIA was one of the first chronic respiratory disease guidelines to adopt the GRADE (Grading of Recommendation, Assessment, Development and Evaluation) approach, an advanced evidence evaluation and development approach for guidelines [16, 81-83]. GRADE-based guidelines are available for AR from other organizations and their recommendations are similar [16-18]. However, a limitation of GRADE is that evidence often lacks applicability because the populations studied do not reflect most of the patients seen in primary care [84]. The GRADE recommendations are often based on RCT in which patients regularly use their treatment, whereas most AR or asthma patients are non-adherent. GRADE rarely includes recommendations based on implementation research.

The more recently completed work by the GRADE working group on its Evidence to Decision Frameworks requires that guideline developers regularly address implementation and monitoring strategies [85-89]. Searching for and synthesizing evidence of effective implementation strategies enabled the BTS/ SIGN asthma guideline to make a recommendation on how supported self-management for asthma could be embedded into routine practice [90]. Strategies include proactively engaging and empowering patients, training and motivating professionals as well as providing an environment that promotes self-management and monitors implementation [91]. In AR, cluster-randomized controlled trials have confirmed the overall value of guidelines [92, 93]. However, there has been only one direct testing of individual guideline recommendations in real-life studies in an effort to achieve optimization [94].

Next-generation ARIA-GRADE guidelines should consider testing the recommendations based on the GRADE approach with real-world evidence (RWE) using data obtained by mHealth tools such as MASK in order to confirm the efficiency or to refine current GRADE-based recommendations. The first results of MASK confirm the feasibility of the project [19]. Adherence to treatment is very low as $<5 \%$ of users record symptoms and medications for a period of 2 weeks. This indicates that it is important to further test whether on-demand is equally or even more efficient than regular-continuous treatment and that guidelines should consider both regular and ondemand treatment $[19,95]$.

Guideline recommendations often address isolated questions or focus on a single disease or problem. They should be considered in the context of the many decisions that are made. ICPs try to address the multiple options and iterative changes in a patient's status and problems. Guideline recommendations should support these iterative changes.

The key challenge for conventional treatment guidelines is that available evidence, both from randomized trials and non-randomized studies, does not usually address the complex pathways, but only affects isolated decision points within a pathway. For example, when an oral $\mathrm{H}_{1}$-antihistamine is not achieving symptom control, we propose to replace it by an intra-nasal corticosteroid. However, this is often not the way that studies are designed and not how patients use these medications. 
Assuming that properly developed pathways require evidence, our guidelines must start identifying the best available evidence to support decision points. When the evidence is indirect, which is frequently the case, connecting the relevant decision points and considering all of that evidence together results in low certainty on the overall structure and timing of an ICP.

The next-generation guidelines, if complemented by the intelligent use of tools such as MASK, which records patients' symptoms and provides advice at given time points to follow ICPs, could exemplify unique new tools to both implement and evaluate recommendations in the context of pathways. Studies should be carried out in which patients are randomized to ICPs or to follow ARIA recommendations that are not presented as pathways. Such studies will provide both information on the use of the recommendations and on the usefulness of the pathways. Through implementation of recommendations, we will be able to increase our certainty in the evidence by evaluating the entire pathway and measuring outcomes in direct population-based studies that record what patients do as opposed to what clinicians prescribe (and patients do not do).

\section{Study proposals of ARIA phase $\mathbf{4}$ and POLLAR}

ARIA Phase 4 is the change management strategy for AR and asthma [96]. POLLAR is an EIT-Health (European Institute for Innovation and technology) project which aims to better understand, prevent and manage the impact of air pollution and allergen exposure on airway diseases [57]. POLLAR will use the MASK App, which is a Good Practice [64]. One of the POLLAR work-packages is the development of ICPs integrating aerobiology and air pollution. This will be developed using a stepwise approach centred around the patient. The four-step project is a WHO Global Alliance against Chronic Respiratory Diseases (GARD) demonstration project.

Step 1: First meeting (December 3, 2018, Paris): Development of next-generation ICPs with a focus on self-management, pharmacy care and next-generation guidelines

The Paris meeting addressed a number of areas as delineated below (Fig. 3).

Step 2: 2019-2021: Further development and implementation of next-generation ICPs

1. Develop a strategic and practical approach to improving patient autonomy and self-management programmes.
2. Deploy to other chronic respiratory diseases (asthma, COPD and rhinosinusitis [97]) and NCDs developing a multimorbidity App based on MASK expertise and experience.

3. Develop documents for specific age groups: preschool and school children, older adults.

4. Establish a best practice across several regions in the EU linking the study to policy makers aiming to improve air quality and outcomes in their population.

Step 3: Second meeting (December 2019): Embedding environmental data in next-generation ICPs

Using the results obtained by POLLAR for air pollution, a second meeting will be held to integrate aerobiology and air pollution data in mobile technology and to propose ICPs for the prevention of severe exacerbations and asthma during peaks of allergens and/or pollution. This meeting will also consider the deployment to other chronic diseases (Fig. 4) and the impact of biodiversity in chronic diseases [98].

\section{Embedding next-generation care pathways in the EU and global political agendas for allergic and chronic respiratory diseases}

The Polish Presidency of the EU Council (2011) targeted CRDs in children to promote their early recognition, prevention and management to ultimately impact active and healthy ageing (AHA) [99]. The developmental determinants of CRDs in ageing were reinforced during the Cyprus Presidency of the EU Council "Healthy ageing across the lifecycle" (2012) [100] and an EU-NIH meeting held in Montpellier (2013) [101].

The objective of AIRWAYS-ICPs [102] was to launch a collaboration to develop multi-sectoral ICPs for CRDs in European countries and regions. AIRWAYS-ICPs was initiated in 2014 by the European Innovation Partnership on Active and Healthy Ageing (EIP on AHA, DG Santé and DG CONNECT) [103] as a GARD (Global Alliance against Chronic Respiratory Diseases) demonstration project [104]. In collaboration with GARD, the Directorate General of Health of Portugal, the EIP on AHA and the Région Occitanie (France), a high-level meeting was organized July 1, 2015 with all major European scientific societies and patient's organizations in Lisbon to review the implementation results of AIRWAYS ICPs [105].

Euforea (European Forum for Research and Education in Allergy and Airway Diseases) [56] proposed an annual stepwise strategy at the EU or ministerial levels. A European Symposium on Precision Medicine in Allergy and Airways Diseases was held at the EU Parliament October 14, 2015 [106]. Another EU Parliament meeting was held 


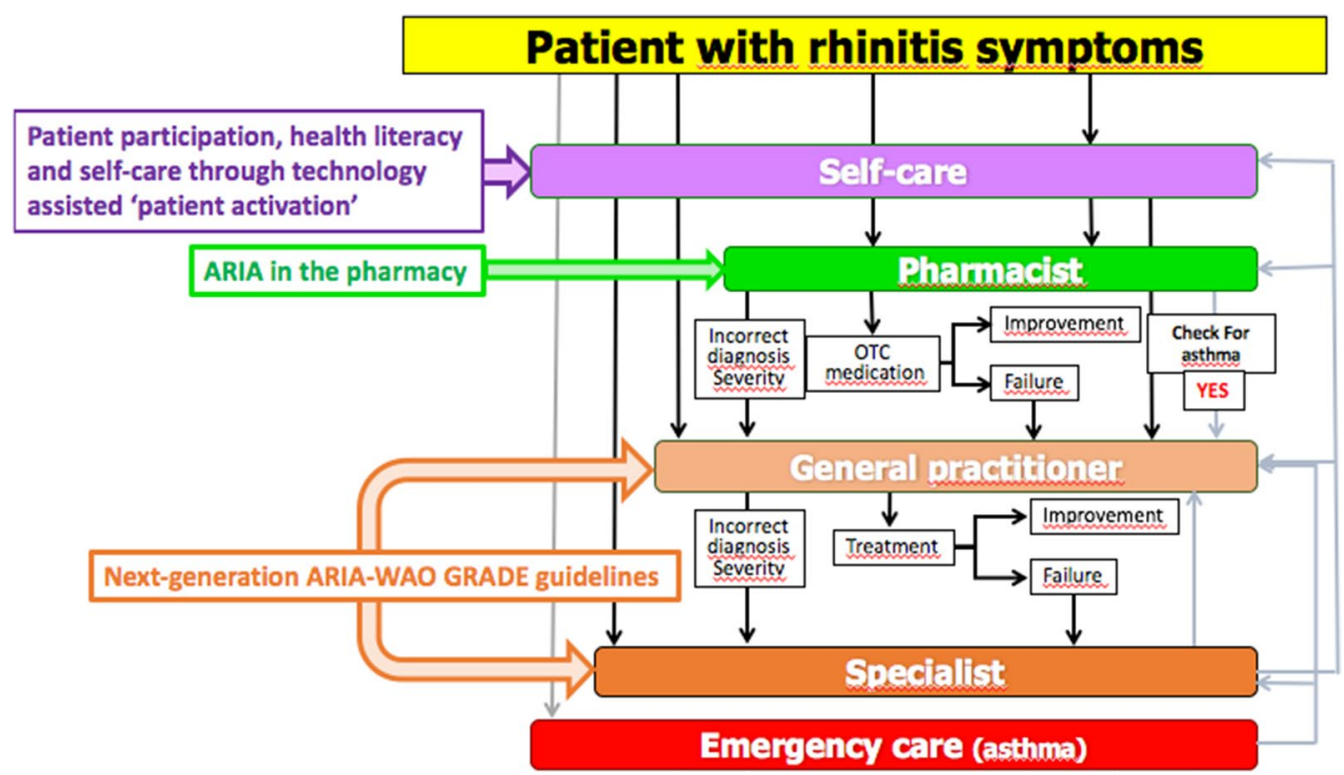

Fig. 3 Next-generation ICPs for rhinitis and asthma multi-morbidity

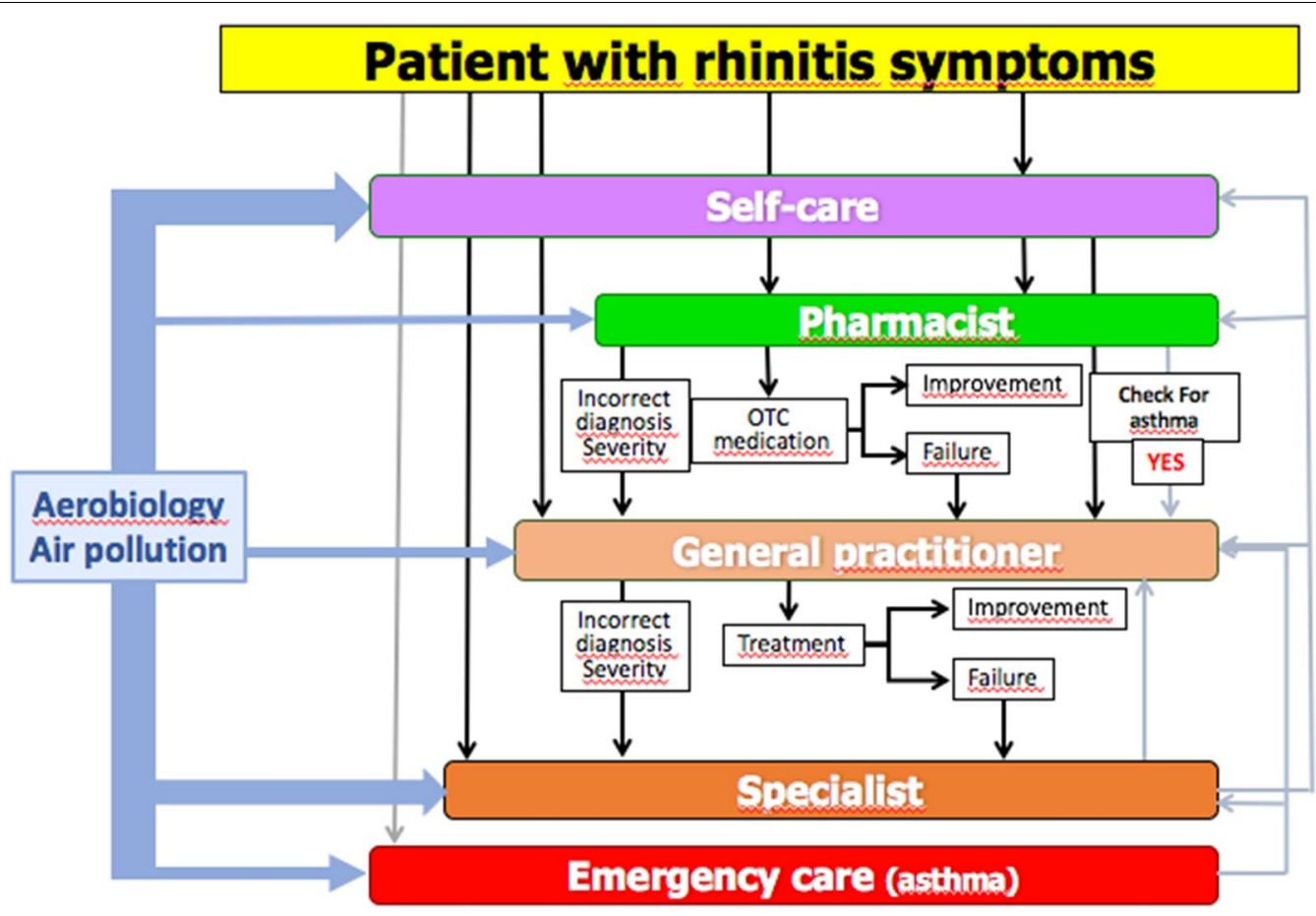

Fig. 4 Embedding aerobiology and air pollution in ICPS

in Brussels March 29, 2017 on the Prevention and SelfManagement of CRDs using novel mobile health tools $[37,56,97]$.

POLLAR (Impact of air POLLution on Asthma and Rhinitis, EIT Health) is focusing on the impact of allergens and air pollution on airway diseases and aims to propose novel ICPs integrating pollution, sleep and patients' literacy and to assess the societal implications of the interaction [57]. 
Euforea organized an EU Summit in Vilnius, Lithuania (March 2018) in collaboration with the Ministers of Health of Lithuania, Moldova, Georgia and Ukraine. The aim was to discuss and start the implementation of the POLLAR concepts, and to deploy it to EU neighboring countries. The Vilnius Declaration on Chronic Respiratory Diseases proposed multisectoral ICPs embedding guided self-management, mHealth and air pollution in CRDs [107].

The joint meeting discussed in this report (December 3 , 2018) proposed next-generation care pathways based on the Vilnius Declaration.

MASK has been selected by the European Commission's Directorate-General for Health and Food Safety (DG SANTE) and the newly-established Commission Expert Group "Steering Group on Health Promotion, Disease Prevention and Management of Non-Communicable Diseases" as a Good Practice (GP) in the field of digitally-enabled, integrated, person-centred care.

On May 3, 2019, a Euforea-led meeting took place in the Parliament of Malta to review the results of the December 3 meeting and to propose practical strategies at the EU and global levels with GARD.

This new next-generation care pathway is completely aligned with the recommendations issued by the Thematic Network SHAFE-Smart Healthy Age-Friendly Environments (approved by the European Commission-DG SANTE and DG CONNECT)-on its Joint Statement delivered 12th November 2018. The Statement underlined the need to patient empowerment and active involvement in its healthcare process and also urged the use of lifestyle medicine that provides effective impact on the patient's wellbeing.

\section{Conclusions}

There is a need to support the digital transformation of health and care with integrated care. An innovative patient-centered approach is proposed by the ARIA expert group for rhinitis and asthma multimorbidity to be scaled up to chronic diseases.

\section{Additional file}

Additional file 1. The MASK Study Group.

\section{Abbreviations}

AIRWAYS ICPS: integrated care pathways for airway diseases; AR: allergic rhinitis; ARIA: Allergic Rhinitis and its Impact on Asthma; BTS/SIGN: British Thoracic Society/Scottish Intercollegiate Guidelines Network; CRD: chronic respiratory diseases; EIP on AHA: European Innovation Partnership on Active and Healthy Ageing; EIT-Health: European Institute for Innovation and technology-Health;
Euforea: European Forum for Research and Education in Allergy and Airway Diseases; GARD: Global Alliance against Chronic Respiratory Diseases; GDPR: General Data Privacy Regulation; GLASS-ARIA: Global Allergy Simple Solution; GP: general practitioner; GRADE: Grading of Recommendation, Assessment, Development and Evaluation; ICP: integrated care pathways; MASK: Mobile Airways Sentinel Network; MHealth: mobile health; OTC: over-the-counter; PG: pocket guides; POLLAR: Impact of Air POLLution in Asthma and Rhinitis; RWE: Real World Evidence; SDM: shared decision making; WAO : World Allergy Organization; WHO: World Health Organization.

\section{Acknowledgements}

Dr. Togias' co-authorship of this publication does not constitute endorsement by the US National Institute of Allergy and Infectious Diseases or by any other United States government agency.

\section{MASK Study group}

See Additional file 1.

\section{Authors' contributions}

All authors are MASK members and have contributed to the design of the project. Many authors also included users and disseminated the project in their own country. Moreover, JB, HJ, AT, ME, TZ, IA, IJA, JMA, CB, SBA, IB, GB, EC, AAC, WC, WJF, JF, MI, LK, VK, LTT, DLL, DL, OML, EM, JM, YO, NP, NPT, HP, CR, BS, STS, IT, AV, AAM, MTV, SW, SW, XB, AB, SB, NB, GWC, VC, AMC, LC, AMCS, DC, EC, ME, GM, JM, EM, LM, GO, JLP, FP, DS, RvdK, AZ participated in the meeting held in Paris, December 3, 2018. All authors read and approved the final manuscript.

\section{Funding}

Partly funded by POLLAR (Impact of Air POLLution on Asthma and Rhinitis, EIT Health), and ARIA.

\section{Availability of data and materials}

Not applicable.

\section{Ethics approval and consent to participate}

Not applicable.

\section{Consent for publication}

All authors gave their agreement for the publication of the paper.

\section{Competing interests}

Dr. Ansotegui reports personal fees from Mundipharma, Roxall, Sanofi, MSD, Faes Farma, Hikma, UCB, Astra Zeneca, outside the submitted work. Dr. BosnicAnticevich reports grants from TEVA, personal fees from TEVA, Boehringer Ingelheim, AstraZeneca, Sanofi, Mylan, outside the submitted work. Dr. Bousquet reports personal fees and others from Chiesi, Cipla, Hikma, Menarini, Mundipharma, Mylan, Novartis, Sanofi-Aventis, Takeda, Teva, Uriach, others from Kyomed, outside the submitted work. Dr. Boulet reports and Disclosure of potential conflicts of interest-last 3 years. Research grants for participation to multicentre studies, AstraZeneca, Boston Scientific, GlaxoSmithKline, Hoffman La Roche, Novartis, Ono Pharma, Sanofi, Takeda. Support for research projects introduced by the investigator AstraZeneca, Boehringer-Ingelheim, GlaxoSmithKline, Merck, Takeda. Consulting and advisory boards Astra Zeneca, Novartis, Methapharm. Royalties Co-author of "Up-To-Date" (occupational asthma). Nonprofit grants for production of educational materials AstraZeneca, Boehringer-Ingelheim, GlaxoSmithKline, Merck Frosst, Novartis. Conference fees AstraZeneca, GlaxoSmithKline, Merck, Novartis. Support for participation in conferences and meetings Novartis, Takeda. Other participations Past president and Member of the Canadian Thoracic Society Respiratory Guidelines Committee; Chair of the Board of Directors of the Global Initiative for Asthma (GINA). Chair of Global Initiative for Asthma (GINA) Guidelines Dissemination and Implementation Committee; Laval University Chair on Knowledge Transfer, Prevention and Education in Respiratory and Cardiovascular Health; Member of scientific committees for the American College of Chest Physicians, American Thoracic Society, European Respiratory Society and the World Allergy Organization; 1st Vice-President of the Global Asthma Organization "InterAsma". Dr. Casale reports grants and non-financial support from Stallergenes, outside the submitted work. Dr. Cruz reports grants and personal fees from GlaxoSmithKline, personal fees from Boehrinher Ingelheim, AstraZeneca, Novartis, Merk, Sharp \& Dohme, MEDA Pharma, EUROFARMA, Sanofi Aventis, outside the submitted work. Dr. Ebisawa reports personal fees from DBV 
Technologies, Mylan EPD maruho, Shionogi \& CO., Ltd., Kyorin Pharmaceutical Co., Ltd., Thermofisher Diagnostics, Pfizer, Beyer, Nippon Chemifar, Takeda Pharmaceutical Co., Ltd., MSD, outside the submitted work. Dr. Ivancevich reports personal fees from Euro Farma Argentina, Faes Farma, non-financial support from Laboratorios Casasco, outside the submitted work. Dr. Haahtela reports personal fees from Mundipharma, Novartis, and Orion Pharma, outside the submitted work. Dr. Klimek reports grants and personal fees from ALK Abelló, Denmark, Novartis, Switzerland, Allergopharma, Germany, Bionorica, Germany, GSK, Great Britain, Lofarma, Italy, personal fees from MEDA, Sweden, Boehringer Ingelheim, Germany, grants from Biomay, Austria, HAL, Netherlands, LETI, Spain, Roxall, Germany, Bencard, Great Britain, outside the submitted work. V.KV has received payment for consultancy from GSK and for lectures from StallergensGreer, Berlin-CHemie and sponsorship from MYLAN for in the following professional training: ARIA masterclass in allergic rhinitis participation. Dr. Larenas Linnemann reports personal fees from GSK, Astrazeneca, MEDA, Boehringer Ingelheim, Novartis, Grunenthal, UCB, Amstrong, Siegfried, DBV Technologies, MSD, Pfizer., grants from Sanofi, Astrazeneca, Novartis, UCB, GSK, TEVA, Chiesi, Boehringer Ingelheim, outside the submitted work. Dr. Mösges reports personal fees from ALK, grants from ASIT biotech, Leti, BitopAG, Hulka, Ursapharm, Optima; personal fees from allergopharma, Nuvo, Meda, Friulchem, Hexal, Servier, Bayer, Johnson \& Johnson, Klosterfrau, GSK, MSD, FAES, Stada, UCB, Allergy Therapeutics; grants and personal fees from Bencard, Stallergenes; grants, personal fees and non-financial support from Lofarma; non-financial support from Roxall, Atmos, Bionorica, Otonomy, Ferrero; personal fees and non-financial support from Novartis; Dr. Okamoto reports personal fees from Eizai Co., Ltd., Shionogi Co., Ltd., Torii Co., Ltd., GSK, MSD, Kyowa Co., Ltd., grants and personal fees from Kyorin Co., Ltd., Tiho Co, Ltd., grants from Yakuruto Co., Ltd., Yamada Bee Farm, outside the submitted work. Dr. Papadopoulos reports grants from Gerolymatos, personal fees from Hal Allergy B.V., Novartis Pharma AG, Menarini, Hal Allergy B.V., outside the submitted work. Dr. Pépin reports grants from AIR LIQUIDE FOUNDATION, AGIR à dom, ASTRA ZENECA, FISHER \& PAYKEL, MUTUALIA, PHILIPS, RESMED, VITALAIRE, other from AGIR à dom, ASTRA ZENECA, BOEHRINGER INGELHEIM, JAZZ PHARMACEUTICAL, NIGHT BALANCE, PHILIPS, RESMED, SEFAM, outside the submitted work. Dr. Pfaar reports grants and personal fees from ALK-Abelló, Allergopharma Stallergenes Greer, HAL Allergy Holding B.V./HAL Allergie $\mathrm{GmbH}$, Bencard Allergie $\mathrm{GmbH} /$ Allergy Therapeutics, Lofarma, grants from Biomay, ASIT Biotech Tools S.A, Laboratorios LETI/LETI Pharma, Anergis S.A., grants from Nuvo, Circassia, Glaxo Smith Kline, personal fees from Novartis Pharma, MEDA Pharma, Mobile Chamber Experts (a GA2LEN Partner), PohlBoskamp, Indoor Biotechnologies, grants from, outside the submitted work. Dr. Todo-Bom reports grants and personal fees from Novartis, Mundipharma, GSK Teva Pharma, personal fees from AstraZeneca, grants from Leti, outside the submitted work. Dr. Tsiligianni reports advisory boards from Boehringer Ingelheim and Novartis and a grant from GSK, outside the submitted work. Dr. Wallace reports and Indicates that she is the co-chair of the Joint Task Force on Practice Parameters, a task force composed of 12 members of the American Academy of Allergy, Asthma, and Immunology and the American College of Allergy, Asthma, and Immunology. Dr. Waserman reports other from CSL Behring, Shire, AstraZeneca,Teva, Meda, Merck, outside the submitted work. Dr. Zuberbier reports and Organizational affiliations: Commitee member: WHO-Initiative "Allergic Rhinitis and Its Impact on Asthma" (ARIA). Member of the Board: German Society for Allergy and Clinical Immunology (DGAKI). Head: European Centre for Allergy Research Foundation (ECARF). Secretary General: Global Allergy and Asthma European Network (GA2LEN). Member: Committee on Allergy Diagnosis and Molecular Allergology, World Allergy Organization (WAO).

\section{Author details}

${ }^{1}$ MACVIA-France, Fondation Partenariale FMC VIA-LR, CHU, 34295 Montpellier Cedex 5, France. ${ }^{2}$ INSERM U 1168, VIMA: Ageing and Chronic Diseases Epidemiological and Public Health Approaches, Villejuif Université Versailles St-Quentin-en-Yvelines, UMR-S 1168, Montigny Le Bretonneux, France. ${ }^{3}$ European Forum for Research and Education in Allergy and Airway Diseases (EUFOREA), Brussels, Belgium. ${ }^{4}$ Charité-Universitätsmedizin Berlin, Corporate Member of Freie Universität Berlin, Humboldt-Uniersität zu Berlin, Berlin, Germany. ${ }^{5}$ Department of Dermatology and Allergy Member of GA2LEN, Comprehensive Allergy-Centre, Berlin Institute of Health, Berlin, Germany. ${ }^{6}$ Department of Clinical Epidemiology and Biostatistics, McMaster University, Hamilton, ON, Canada. ${ }^{7}$ Division of Allergy, Immunology, and Transplantation (DAIT), National Institute of Allergy and Infectious Diseases, NIH, Bethesda,
USA. ${ }^{8}$ National Institute for Health and Welfare, Helsinki, Finland. ${ }^{9}$ Dept of Otorhinolaryngology, Univ Hospitals Leuven, Louvain, Belgium. ${ }^{10}$ Academic Medical Center, Univ of Amsterdam, Amsterdam, The Netherlands. ${ }^{11}$ Faculty of Medicine, Transylvania University, Brasov, Romania. ${ }^{12}$ Department of Allergy and Immunology, Hospital Quirónsalud Bizkaia, Erandio, Spain. ${ }^{13}$ ISGlobAL, Centre for Research in Environmental Epidemiology (CREAL), Barcelona, Spain. ${ }^{14}$ IMIM (Hospital del Mar Research Institute), Barcelona, Spain. ${ }^{15} \mathrm{CIBER}$ Epidemiología y Salud Pública (CIBERESP), Barcelona, Spain. ${ }^{16}$ Universitat Pompeu Fabra (UPF), Barcelona, Spain. ${ }^{17}$ Upper Airways Research Laboratory, ENT Dept, Ghent University Hospital, Ghent, Belgium. ${ }^{18}$ Dept of Otolaryngology, Head and Neck Surgery, University of Mainz, Mainz, Germany. ${ }^{19}$ Hospital Civil de Guadalajara Dr Juan I Menchaca, Guadalarara, Mexico. ${ }^{20} \mathrm{iQ} 4 \mathrm{U}$ Consultants Ltd, London, UK. ${ }^{21}$ Woolcock Institute of Medical Research, University of Sydney, Sydney, Australia. ${ }^{22}$ Woolcock Emphysema Centre, Sydney, Australia. ${ }^{23}$ Sydney Local Health District, Glebe, NSW, Australia. ${ }^{24}$ La Rochelle, France. ${ }^{25}$ Quebec Heart and Lung Institute, Laval University, Quebec City, QC, Canada. ${ }^{26}$ EIT Health France, Paris, France. ${ }^{27}$ Dept of Respiratory Medicine, Ghent University Hospital, Ghent, Belgium. ${ }^{28}$ Department of Public Health and Primary Care, Leiden University Medical Center, Leiden, The Netherlands. ${ }^{29}$ UCIBIO, REQUINTE, Faculty of Pharmacy and Competence Center on Active and Healthy Ageing of University of Porto (Porto4Ageing), Porto, Portugal. ${ }^{30}$ ProAR-Nucleo de Excelencia em Asma, Federal University of Bahia, Bahia, Brazil. ${ }^{31}$ WHO GARD Planning Group, Salvador, Brazil. 32 Medical Consulting Czarlewski, Levallois, France. ${ }^{33}$ Department of Otorhinolaryngology, Amsterdam University Medical Centres, AMC, Amsterdam, The Netherlands. ${ }^{34}$ CINTESIS, Center for Research in Health Technology and Information Systems, Faculdade de Medicina da Universidade do Porto, Porto, Portugal. ${ }^{35}$ Medida, Lda Porto, Portugal. ${ }^{36}$ ERS President 2017-2018, Athens Chest Hospital, 7th Resp Med Dept and Asthma Center, Athens, Greece. ${ }^{37}$ Skin and Allergy Hospital, Helsinki University Hospital and University of Helsinki, Helsinki, Finland. ${ }^{38}$ Division for Health Innovation, Campania Region and Federico II University Hospital Naples (R \&D and DISMET), Naples, Italy. ${ }^{39}$ Center for Rhinology and Allergology, Wiesbaden, Germany. ${ }^{40}$ Division of Internal Medicine, Asthma and Allergy, Barlicki University Hospital, Medical University of Lodz, Łódź, Poland. ${ }^{41}$ Faculty of Medicine, Vilnius University, Vilnius, Lithuania. ${ }^{42}$ University of Medicine and Pharmacy, Hochiminh City, Vietnam. ${ }^{43}$ Center of Excellence in Asthma and Allergy, Médica Sur Clinical Foundation and Hospital, México City, Mexico. ${ }^{44} \mathrm{KY}$ Yomed INNOV, Montpellier, France. ${ }^{45}$ Faculty of Health Sciences and CICS-UBI, Health Sciences Research Centre, University of Beira Interior, Covilhã, Portugal. ${ }^{46} \mathrm{CIRFF}$, Federico II University, Naples, Italy. ${ }^{47}$ Rhinology Unit \& Smell Clinic, ENT Department, Hospital Clínic, Barcelona, Spain. ${ }^{48}$ Clinical \& Experimental Respiratory Immunoallergy, IDIBAPS, CIBERES, University of Barcelona, Barcelona, Spain. ${ }^{49}$ Dept of Otorhinolaryngology, Chiba University Hospital, Chiba, Japan. ${ }^{50}$ Division of Infection, Immunity \& Respiratory Medicine, Royal Manchester Children's Hospital, University of Manchester, Manchester, UK. ${ }^{51}$ Allergy Department, 2nd Pediatric Clinic, Athens General Children's Hospital "P\&A Kyriakou", University of Athens, Athens, Greece. ${ }^{52}$ Allergy Department, Pasteur Institute, Paris, France. ${ }^{53}$ Conseil Général de l'Economie Ministère de I'Economie, de l'Industrie et du Numérique, Paris, France. ${ }^{54}$ The Usher Institute of Population Health Sciences and Informatics, The University of Edinburgh, Edinburgh, UK. ${ }^{55}$ Pneumologie et Soins Intensifs Respiratoires, Hôpitaux Universitaires Paris, Centre Hôpital Cochin, Paris, France. ${ }^{56}$ Department of Internal Medicine, Medical University of Graz, Graz, Austria. ${ }^{57}$ Association Asthme et Allergie, Paris, France. ${ }^{58}$ Department of Prevention of Environmental Hazards and Allergology, Medical University of Warsaw, Warsaw, Poland. ${ }^{59}$ Health Planning Unit, Department of Social Medicine, Faculty of Medicine, University of Crete, Crete, Greece. ${ }^{60}$ International Primary Care Respiratory Group IPCRG, Aberdeen, Scotland, UK. ${ }^{61}$ Institute of Clinical Medicine \& Institute of Health Sciences, Vilnius University Faculty of Medicine, Vilnius, Lithuania. ${ }^{62}$ Department of Lung Diseases and Clinical Immunology, University of Turku and Terveystalo Allergy Clinic, Turku, Finland. ${ }^{63}$ FILHA, Finnish Lung Association, Helsinki, Finland. ${ }^{64}$ Unit of Geriatric Immunoallergology, University of Bari Medical School, Bari, Italy. ${ }^{65}$ Asthma UK, Mansell Street, London, UK. ${ }^{66}$ Swiss Institute of Allergy and Asthma Research (SIAF), University of Zurich, Davos, Switzerland. ${ }^{67}$ Epidemiology of Allergic and Respiratory Diseases, Department Institute Pierre Louis of Epidemiology and Public Health, INSERM and Sorbonne Université, Medical School Saint Antoine, Paris, France. ${ }^{68}$ Department of Medicine, University of Cape Town, Cape Town, South Africa. ${ }^{69}$ Dept of Respiratory Medicine, National Institute of Diseases of the Chest and Hospital, Dhaka, Bangladesh. ${ }^{70}$ National Center 
of Expertise in Cognitive Stimulation (CEN STIMCO), Broca Hospital, Paris, France. ${ }^{71}$ Department of Biochemistry and Clinical Chemistry, Faculty of Pharmacy with the Division of Laboratory Medicine, Warsaw Medical University, Warsaw, Poland. ${ }^{72}$ Global Alliance against Chronic Respiratory Diseases (WHO GARD), Joensuu, Finland. ${ }^{73}$ Department of Dermatology and Allergy Centre, Odense University Hospital, Odense Research Center for Anaphylaxis (ORCA), Odense, Denmark. ${ }^{74}$ Termofischer Scientific, Uppsala, Sweden. ${ }^{75}$ Department of Respiratory Medicine and Allergology, University Hospital, Lund, Sweden. ${ }^{76}$ Department of Geriatrics, Montpellier University hospital, Montpellier, France. ${ }^{77}$ EA 2991 Euromov, University Montpellier, Montpellier, France. ${ }^{78}$ UOC Pneumologia, Istituto di Medicina Interna, F Policlinico Gemelli IRCCS, Università Cattolica del Sacro Cuore, Rome, Italy. ${ }^{79}$ National Heart and Lung Institute, Royal Brompton Hospital \& Imperial College, London, UK. ${ }^{80} \mathrm{CHU}$, Dijon, France. ${ }^{81}$ Clinical Medicine, Laval's University, Quebec City, Canada. ${ }^{82}$ Medicine Department, Hôpital de la Malbaie, Quebec city, QC, Canada. ${ }^{83}$ Department of Clinical Pharmacy of Lithuanian, University of Health, Kaunas, Lithuania. ${ }^{84}$ Institute of Lung Health, Respiratory Biomedical Unit, University Hospitals of Leicester NHS Trust, Leicestershire, UK. ${ }^{85}$ Department of Infection, Immunity and Inflammation, University of Leicester, Leicester, UK. ${ }^{86}$ Universitätsmedizin der Johannes Gutenberg-Universität Mainz, Mainz, Germany. ${ }^{87}$ Municipality Pharmacy, Sarno, Italy ${ }^{88}$ Personalized Medicine Clinic Asthma \& Allergy, Humanitas University, Humanitas Research Hospital, Rozzano, Milan, Italy. ${ }^{89}$ Allergy Section, Department of Internal Medicine, Hospital Vall d'Hebron \& ARADyAL Research Network, Barcelona, Spain. ${ }^{90}$ Regional Ministry of Health of Andalusia, Seville, Spain. ${ }^{91}$ Allergy and Asthma Associates of Southern California, Mission Viejo, CA, USA. ${ }^{92}$ ASA-Advanced Solutions Accelerator, Clapiers, France. ${ }^{93}$ Division of Allergy/Immunology, University of South Florida, Tampa, FL, USA. ${ }^{94}$ SOS Allergology and Clinical Immunology, USL Toscana Centro, Prato, Italy. ${ }^{95}$ Allergy and Immunology Laboratory, Metropolitan University, Simon Bolivar University, Barranquilla, Colombia. ${ }^{96}$ SLaai, Sociedad Latinoamericana de Allergia, Asma e Immunologia, Barranquilla, Colombia. ${ }^{97}$ Chachava Clinic, David Tvildiani Medical University-AIETI Medical School, Grigol Robakidze University, Tbilisi, Georgia. ${ }^{98}$ Medical Faculty, ENT Department, Eskisehir Osmangazi University, Eskisehir, Turkey. ${ }^{99}$ Department of Health, Social Services and Public Safety, Belfast, Northern Ireland, UK. ${ }^{100}$ Life and Health Sciences Research Institute (ICVS), School of Medicine, University of Minho, Braga, Portugal. ${ }^{101}$ PT Government Associate Laboratory, ICVS/3B's, Braga/Guimarães, Portugal. ${ }^{102}$ Ecole des Mines, Alès, France. ${ }^{103}$ Centre for Respiratory Medicine and Allergy, Institute of Inflammation and Repair, University of Manchester and University Hospital of South Manchester, Manchester, UK. ${ }^{104}$ Division of Respiratory and Allergic Diseases, Department of Respiratory Diseases, High Specialty Hospital A.Cardarelli, Naples, Italy. ${ }^{105}$ Allergy Service, University Hospital of Federal University of Santa Catarina (HU-UFSC), Florianópolis, Brazil. ${ }^{106}$ Cáritas Diocesana de Coimbra, Coimbra, Portugal. ${ }^{107}$ Ageing@Coimbra EIP-AHA Reference Site, Coimbra, Portugal. ${ }^{108}$ Medical Faculty Skopje, University Clinic of Pulmonology and Allergy, Skopje, Republic of Macedonia. ${ }^{109}$ Sleep Unit, Department of Neurology, Hôpital Gui-de-Chauliac Montpellier, Inserm U1061, Montpellier, France. ${ }^{110}$ AQUAS, Barcelna, Spain. ${ }^{111}$ EUREGHA, European Regional and Local Health Association, Brussels, Belgium. ${ }^{112}$ Department of Medicine, Surgery and Dentistry "Scuola Medica Salernitana", University of Salerno, Salerno, Italy. 113 UPRES EA220, Pôle des Maladies des Voies Respiratoires, Hôpital Foch, Université Paris-Saclay, Suresnes, France. ${ }^{114}$ Farmacie Dei Golfi Group, Massa Lubrense, Italy. ${ }^{115}$ Section of Allergy and Immunology, Saint Louis University School of Medicine, Saint Louis, MO, USA. ${ }^{116}$ Clinic of Infectious, Chest Diseases, Dermatology and Allergology, Vilnius University, Vilnius, Lithuania. ${ }^{117}$ Clinical Reserch Center for Allergy and Rheumatology, Sagamihara National Hospital, Sagamihara, Japan. ${ }^{118}$ Pediatric Allergy and Immunology Unit, Children's hospital, Ain Shams University, Cairo, Egypt. ${ }^{119}$ Clinic of Children's Diseases, Faculty of Medicine, Vilnius University, Vilnius, Lithuania. ${ }^{120} \mathrm{Global}$ Allergy and Asthma Platform GAAPP, Vienna, Austria. ${ }^{121}$ Division of Allergy, Department of Pediatric Medicine, The Bambino Gesù Children's Research Hospital Holy See, Rome, Italy. ${ }^{122}$ Reims, France. ${ }^{123}$ Department of Pulmonary Diseases, Istanbul University-Cerrahpasa, Cerrahpasa Faculty of Medicine, Istambul, Turkey. ${ }^{124}$ Allergy Unit, Department of Dermatology, University Hospital of Zurich, Zurich, Switzerland. ${ }^{125}$ National Center for Disease Control and Public Health of Georgia, Tbilisi, Georgia. ${ }^{26}$ Allergy \& Asthma Unit, Hospital San Bernardo Salta, Salta, Argentina. ${ }^{127}$ Universidad Autónoma de Nuevo León, San Nicolás de los Garza, Mexico. ${ }^{128}$ Center of Allergy and Immunology, Georgian Association of Allergology and Clinical
Immunology, Tbilisi, Georgia. ${ }^{129}$ Institute of Health Policy and Management iBMG, Erasmus University, Rotterdam, The Netherlands. ${ }^{130}$ Immunology and Allergy Division, Clinical Hospital, University of Chile, Santiago, Chile. ${ }^{131}$ Centich: Centre d'Expertise National des Technologies de I'Information et de la Communication pour l'Autonomie, Gérontopôle Autonomie Longévité des Pays de la Loire, Conseil Régional des Pays de la Loire, Centre d'Expertise Partenariat Européen d'Innovation pour un Vieillissement Actif et en Bonne Santé, Nantes, France. ${ }^{132}$ Department of Paediatrics and Child Health, University College Cork, Cork, Ireland. ${ }^{133}$ Université Paris-Sud; Service de Pneumologie, Hôpital Bicêtre, Inserm UMR_S999, Le Kremlin Bicêtre, France. ${ }^{134}$ Department of Medicine and Surgery, University of Salerno, Baronissi, Italy. 135 Servicio de Alergia e Immunologia, Clinica Santa Isabel, Buenos Aires, Argentina. ${ }^{136}$ Hallym University College of Medicine, Hallym University Sacred Heart Hospital, Anyang, Gyeonggi-do, South Korea. ${ }^{137}$ Department of Clinical Immunology, Wrocław Medical University, Wrocław, Poland. ${ }^{138}$ Ukrainian Medical Stomatological Academy, Poltava, Ukraine. ${ }^{139}$ Pediatric Allergy and Asthma Unit, Hacettepe University School of Medicine, Ankara, Turkey. ${ }^{140}$ First Department of Family Medicine, Medical University of Lodz, Łódź, Poland. ${ }^{141}$ Institute of Social Medicine, Epidemiology and Health Economics, Charité-Universitätsmedizin Berlin, Berlin, Germany. ${ }^{142}$ Institute for Clinical Epidemiology and Biometry, University of Wuerzburg, Würzburg, Germany. ${ }_{143}$ National Research Center, Institute of Immunology, Federal Medicobiological Agency, Laboratory of Molecular Immunology, Moscow, Russian Federation. ${ }^{144}$ GARD Chairman, Geneva, Switzerland. ${ }^{145}$ Allergy \& Asthma Center Westend, Berlin, Germany. ${ }^{146}$ Department of Immunology and Allergy, Healthy Ageing Research Center, Medical University of Lodz, Łódź, Poland. ${ }^{147}$ Department of Clinical Science and Education, Södersjukhuset, Karolinska Institutet, Stockholm, Sweden. ${ }^{148}$ Sach's Children and Youth Hospital, Södersjukhuset, Stockholm, Sweden. ${ }^{149}$ Mattone Internazionale Program, Veneto Region, Italy. ${ }^{150}$ Departments of Internal Medicine and Pediatrics (Divisions of Allergy and Immunology), University of Tennessee College of Medicine, Germantown, TN, USA. 151 Scottish Centre for Respiratory Research, Cardiovascular \& Diabetes Medicine, Medical Research Institute, Ninewells Hospital, University of Dundee, Dundee, UK. ${ }^{152}$ Department of Paediatrics, Oslo University Hospital, Oslo, Norway. ${ }^{153}$ Faculty of Medicine, Institute of Clinical Medicine, University of Oslo, Oslo, Norway. ${ }^{154}$ Imunoalergologia, Centro Hospitalar Universitário de Coimbra and Faculty of Medicine, University of Coimbra, Coimbra, Portugal. ${ }^{155}$ Department of Pulmonary Medicine, CHU Sart-Tilman, and GIGA I3 Research Group, Liege, Belgium. ${ }^{156}$ DG for Health and Social Care, Scottish Government, Edinburgh, UK. ${ }^{157}$ Department of Pulmonary Medicine, Rashid Hospital, Dubai, UAE. ${ }^{158}$ Coimbra Institute for Clinical and Biomedical Research (iCBR), Faculty of Medicine, University of Coimbra, Coimbra, Portugal. ${ }^{159}$ Department of Medicine (RCSI), Bon Secours Hospital, Glasnevin, Dublin, Ireland.

${ }^{160}$ Kronikgune, International Centre of Excellence in Chronicity Research Barakaldo, Barakaldo, Bizkaia, Spain. ${ }^{161}$ Division of Clinical Immunology and Allergy, Laboratory of Behavioral Immunology Research, The University of Mississippi Medical Center, Jackson, MS, USA. ${ }^{162}$ Tobacco Control Research Centre, Iranian Anti Tobacco Association, Tehran, Iran. ${ }^{163}$ Argentine Association of Allergy and Clinical Immunology, Buenos Aires, Argentina. ${ }^{164}$ Department of Pediatric Pneumology and Immunology, AG Molecular Allergology and Immunomodulation, Charité Medical University, Berlin, Germany. ${ }^{165}$ Institute of Environmental Medicine, Karolinska Institutet, Stockholm, Sweden. ${ }^{166}$ PNDR, Portuguese National Programme for Respiratory Diseases, Faculdade de Medicina de Lisboa, Lisbon, Portugal. ${ }^{167}$ Allergy and Asthma Medical Group and Research Center, San Diego, CA, USA.

${ }^{168}$ Department of Physiology, CHRU, University Montpellier, Vice President for Research, PhyMedExp, INSERM U1046, CNRS, UMR 9214, Montpellier, France. ${ }^{169}$ Croatian Pulmonary Society, Zagreb, Croatia. ${ }^{170}$ National Institute of Pneumology M Nasta, Bucharest, Romania. ${ }^{171}$ Clinic for Pulmonary Diseases, Clinical Center of Serbia, Faculty of Medicine, University of Belgrade, Serbian Association for Asthma and COPD, Belgrade, Serbia. ${ }^{172}$ Regione Piemonte, Turin, Italy. ${ }^{173}$ Mexico City, Mexico. ${ }^{174}$ National Center for Research in Chronic Respiratory Diseases, Tishreen University School of Medicine, Latakia, Syria. ${ }^{175}$ Syrian Private University, Damascus, Syria. ${ }^{176}$ Faculty of Medicine and Surgery, University of Medicine, La Valette, Malta. ${ }^{177}$ Department of Medical Sciences, Allergy and Clinical Immunology Unit, University of Torino \& Mauriziano Hospital, Turin, Italy. ${ }^{178}$ Allergy Center, CUF Descobertas Hospital, Lisbon, Portugal. ${ }^{179}$ Institute of Medical Statistics, and Computational Biology, Medical Faculty, University of Cologne, Cologne, Germany. ${ }^{180} \mathrm{CRI}$-Clinical Research International-Ltd, Hamburg, Germany. ${ }^{181}$ Danish 
Commitee for Health Education, Copenhagen East, Denmark. ${ }^{182}$ Food Allergy Referral Centre Veneto Region, Department of Women and Child Health, Padua General University Hospital, Padua, Italy. ${ }^{183}$ MedScript Ltd, Paraparomu, New Zealand. ${ }^{184}$ OPC, Cambridge, UK. ${ }^{185}$ Johns Hopkins School of Medicine, Baltimore, MD, USA. ${ }^{186}$ Consortium of Pharmacies and Services COSAFER, Salerno, Italy. ${ }^{187}$ Scientific Centre of Children's Health under the Russian Academy of Medical Sciences, Moscow, Russia. ${ }^{188}$ Center of Allergy, Immunology and Respiratory Diseases, Santa Fe, Argentina. ${ }^{189}$ Center for Allergy and Immunology, Santa Fe, Argentina. ${ }^{190}$ Hospital of the Hospitaller Brothers in Buda, Budapest, Hungary. ${ }^{191}$ Die Hautambulanz and Rothhaar Study Center, Berlin, Germany. ${ }^{192}$ Department of Pharmacy, University of Naples Federico II, Naples, Italy. ${ }^{193}$ ENT Department, University Hospital of Kinshasa, Kinshasa, Congo. ${ }^{194}$ Department of Allergy, Immunology and Respiratory Medicine, Alfred Hospital and Central Clinical School, Monash University, Melbourne, VIC, Australia. ${ }^{195}$ Dept of Otolaryngology, Nippon Medical School, Tokyo, Japan. ${ }^{196}$ Centre Hospitalier Universitaire Pédiatrique Charles de Gaulle, Ouagadougou, Burkina Faso. ${ }^{197}$ Dept of Comparative Medicine, Messerli Research Institute of the University of Veterinary Medicine and Medical University, Vienna, Austria. ${ }^{198}$ EFA European Federation of Allergy and Airways Diseases Patients' Associations, Brussels, Belgium. ${ }^{199}$ Department of Immunology and Allergology, Faculty of Medicine and Faculty Hospital in Pilsen, Charles University in Prague, Pilsen, Czech Republic. ${ }^{200}$ Department of Allergy and Clinical Immunology, Ajou University School of Medicine, Suwon, South Korea. ${ }^{201}$ Laboratoire HP2, Université Grenoble Alpes, Grenoble, France. ${ }^{202}$ INSERM, U1042 and CHU de Grenoble, Grenoble, France. ${ }^{203}$ Allergy Unit, CUF-Porto Hospital and Institute, Porto, Portugal. ${ }^{204}$ Center for Research in Health Technologies and Information Systems, CINTESIS, Universidade do Porto, Porto, Portugal. ${ }^{205}$ Maladies Infectieuses et immunitaires, CHUL, Quebec City, QC, Canada. ${ }^{206}$ Department of Otorhinolaryngology, Head and Neck Surgery, Section of Rhinology and Allergy, University Hospital Marburg, Philipps-Universität Marburg, Marburg, Germany. ${ }^{207}$ Farmacias Holon, Lisbon, Portugal. ${ }^{208}$ Centre for Empowering Patients and Communities, Faulkland, Somerset, UK. ${ }^{209}$ Children's Hospital Srebrnjak, Zagreb, Croatia. ${ }^{210}$ School of Medicine, University J.J. Strossmayer, Osijek, Croatia. ${ }^{211}$ University Hospital 'Sv Ivan Rilski', Sofia, Bulgaria. ${ }^{212}$ Academic Centre of Primary Care, University of Aberdeen, Aberdeen, Scotland, UK. ${ }^{213}$ Research in Real-Life, Cambridge, UK. ${ }^{214}$ Department of Otorhinolaryngology, University of Crete School of Medicine, Heraklion, Greece. ${ }^{215}$ Department of Nephrology and Endocrinology, Karolinska University Hospital, Stockholm, Sweden. ${ }^{216}$ Allergy Unit, Presidio Columbus, Catholic University of Sacred Heart, Rome, Italy. ${ }^{217}$ IRCCS Oasi Maria SS, Troina, Italy. ${ }^{218}$ Hospital de Clinicas, University of Parana, Paraná, Brazil. ${ }^{219}$ Division of Allergy Asthma and Clinical Immunology, Emek Medical Center, Afula, Israel. ${ }^{220}$ Allergy and Respiratory Research Group, The University of Edinburgh, Edinburgh, UK. ${ }^{221}$ Association of Finnish Pharmacists, Helsinki, Finland. ${ }^{222}$ Allergy and Clinical Immunology Department, Centro Médico-Docente la, Trinidad and Clínica El Avila, Caracas, Venezuela. ${ }^{223}$ Sociedad Paraguaya de Alergia Asma e Inmunologia, Asunción, Paraguay. 224 Division of Allergy, Clinical Immunology and Rheumatology, Department of Pediatrics, Federal University of São Paulo, São Paulo, Brazil. ${ }^{225}$ European Health Futures Forum (EHFF), Dromahair, UK. ${ }^{226}$ Kyrgyzstan National Centre of Cardiology and Internal Medicine, Euro-Asian Respiratory Society, Bishkek, Kyrgyzstan. ${ }^{227}$ Department of Respiratory Medicine, University Hospital Olomouc, Olomouc, Czech Republic. ${ }^{228}$ Pulmonary Division, Heart Institute (InCor), Hospital da Clinicas da Faculdade de Medicina da Universidade de Sao Paulo, Sao Paulo, Brazil. ${ }^{229}$ Department of Respiratory Medicine, Hvidovre Hospital \& University of Copenhagen, Copenhagen, Denmark. ${ }^{230}$ RNSA (Réseau National de Surveillance Aérobiologique), Brussieu, France. ${ }^{231}$ Sidkkids Hospitala and Institute of Health Policy, Management and Evaluation, Toronto, Canada. ${ }^{232}$ Department of ENT, Medical University of Graz, Graz, Austria. ${ }^{233}$ Pneumology and Allergy Department CIBERES and Clinical \& Experimental Respiratory Immunoallergy, IDIBAPS, University of Barcelona, Barcelona, Spain. ${ }^{234}$ Division of Immunopathology, Department of Pathophysiology and Allergy Research, Center for Pathophysiology, Infectiology and Immunology, Medical University of Vienna, Vienna, Austria. ${ }^{235}$ NRC Institute of Immunology FMBA of Russia, Moscow, Russia. ${ }^{236}$ Laboratory of Immunopathology, Department of Clinical Immunology and Allergy, Sechenov First Moscow State Medical University, Moscow, Russia. ${ }^{237}$ Montevideo, Uruguay. ${ }^{238}$ Department of Public Health \& Primary Care, Leiden University Medical Center (LUMC), Leiden, The Netherlands. ${ }^{239}$ Department of Obstetrics and Gynaecology, Erasmus MC, University Medical Center, Rotterdam, The Netherlands. ${ }^{240}$ Department of Chest Medicine, Centre Hospitalier Universitaire UCL Namur, Université Catholique de Louvain, Yvoir, Belgium. ${ }^{241}$ Pulmonary Unit, Department of Medical Specialties, Arcispedale SMaria Nuova/IRCCS, AUSL di Reggio Emilia, Reggio Emilia, Italy. ${ }^{242}$ Pulmonary Environmental Epidemiology Unit, CNR Institute of Clinical Physiology, Pisa, Italy. ${ }^{243}$ CNR Institute of Biomedicine and Molecular Immunology "A Monroy", Palermo, Italy. ${ }^{244}$ Nova Southeastern University, Fort Lauderdale, FL, USA. ${ }^{245}$ Dept of Otorhinolaryngology, HNO-Klinik, Universitätsklinikum Düsseldorf, Düsseldorf, Germany. ${ }^{246}$ Department of Otolaryngology, Yong Loo Lin School of Medicine, National University of Singapore, Singapore, Singapore. ${ }^{247}$ Department of Medicine, Clinical Immunology and Allergy, McMaster University, Hamilton, ON, Canada. ${ }^{248}$ Centre for Clinical Research Sörmland, Uppsala University, Eskilstuna, Sweden. ${ }^{249}$ Eshelman School of Pharmacy, University of North Carolina, Chapel Hill, NC, USA. ${ }^{250}$ Cyprus International Institute for Environmental \& Public Health in Association with Harvard School of Public Health, Cyprus University of Technology, Limassol, Cyprus. ${ }^{251}$ Department of Pediatrics, Hospital "Archbishop Makarios III", Nicosia, Cyprus. ${ }^{252}$ Department of Pulmonary Diseases, Celal Bayar University, Faculty of Medicine, Manisa, Turkey. ${ }^{253}$ The Allergy and Asthma Institute, Islamabad, Pakistan. ${ }^{254}$ Department of Paediatrics and Child Health, Red Cross Children's Hospital, Cape Town, South Africa. ${ }^{255}$ MRC Unit on Child \& Adolescent Health, University of Cape Town, Cape Town, South Africa. ${ }^{256}$ Bull DSAS, Echirolles, France. ${ }^{257}$ Universidad Católica de Córdoba, Córdoba, Argentina. ${ }^{258}$ Department of Otolaryngology Head and Neck Surgery, Beijing TongRen Hospital and Beijing Institute of Otolaryngology, Beijing, China. ${ }^{259}$ State Key Laboratory of Respiratory Diseases, Guangzhou Institute of Respiratory Disease, The First Affiliated Hospital of Guangzhou Medical University, Guangzhou, China. ${ }^{260}$ University Clinic of Respiratory and Allergic Diseases, Golnik, Slovenia. ${ }^{261}$ National Hospital Organization, Tokyo National Hospital, Tokyo, Japan.

\section{Received: 15 May 2019 Accepted: 29 July 2019}

Published online: 09 September 2019

\section{References}

1. Bousquet J, Anto JM, Sterk PJ, Adcock IM, Chung KF, Roca J, et al. Systems medicine and integrated care to combat chronic noncommunicable diseases. Genome Med. 2011;3(7):43.

2. Stenberg K, Lauer JA, Gkountouras G, Fitzpatrick C, Stanciole A. Econometric estimation of WHO-CHOICE country-specific costs for inpatient and outpatient health service delivery. Cost Eff Resour Alloc. 2018;16:11.

3. Crespi-Lofton J, Skelton JB. The growing role of biologics and biosimilars in the United States: Perspectives from the APhA Biologics and Biosimilars Stakeholder Conference. J Am Pharm Assoc. 2017;57(5):e15-27.

4. Gronde TV, Uyl-de Groot CA, Pieters T. Addressing the challenge of high-priced prescription drugs in the era of precision medicine: a systematic review of drug life cycles, therapeutic drug markets and regulatory frameworks. PLoS ONE. 2017;12(8):e0182613.

5. Global Burden of Disease Health Financing Collaborator N. Future and potential spending on health 2015-2040: development assistance for health, and government, prepaid private, and out-of-pocket health spending in 184 countries. Lancet. 2017;389(10083):2005-30.

6. Russell J, Greenhalgh T. Affordability as a discursive accomplishment in a changing National Health Service. Soc Sci Med. 2012;75(12):2463-71.

7. Hunter DJ, Erskine J, Small A, McGovern T, Hicks C, Whitty P, et al. Doing transformational change in the English NHS in the context of "big bang" redisorganisation. J Health Organ Manag. 2015;29(1):10-24.

8. Farmanova E, Bonneville L, Bouchard L. Organizational health literacy: review of theories, frameworks, guides, and implementation issues. Inquiry. 2018;55:46958018757848.

9. Campbell H, Hotchkiss R, Bradshaw N, Porteous M. Integrated care pathways. BMJ. 1998;316(7125):133-7.

10. Hujala A, Taskinen H, Rissanen S. In: Richardson E, van Ginneken E, editors. How to support integration to promote care for people with multimorbidity in Europe? European Observatory Policy Briefs. Copenhagen (Denmark); 2017.

11. Palmer K, Marengoni A, Forjaz MJ, Jureviciene E, Laatikainen T, Mammarella F, et al. Multimorbidity care model: recommendations from the consensus meeting of the Joint Action on Chronic Diseases and 
Promoting Healthy Ageing across the Life Cycle (JA-CHRODIS). Health Policy. 2018;122(1):4-11.

12. Overill S. A practical guide to care pathways. J Integr Care. 1998;2:93-8.

13. Chisholm-Burns MA, Kim Lee J, Spivey CA, Slack M, Herrier RN, HallLipsy E, et al. US pharmacists' effect as team members on patient care: systematic review and meta-analyses. Med Care. 2010;48(10):923-33.

14. Lee JK, Slack MK, Martin J, Ehrman C, Chisholm-Burns M. Geriatric patient care by U.S. pharmacists in healthcare teams: systematic review and meta-analyses. J Am Geriatr Soc. 2013;61(7):1119-27.

15. Skypala IJ, de Jong NW, Angier E, Gardner J, Kull I, Ryan D, et al. Promoting and achieving excellence in the delivery of Integrated Allergy Care: the European Academy of Allergy \& Clinical Immunology competencies for allied health professionals working in allergy. Clin Transl Allergy. 2018;8:31.

16. Brozek JL, Bousquet J, Baena-Cagnani CE, Bonini S, Canonica GW, Casale $T B$, et al. Allergic Rhinitis and its Impact on Asthma (ARIA) guidelines: 2010 revision. J Allergy Clin Immunol. 2010;126(3):466-76.

17. Brozek JL, Bousquet J, Agache I, Agarwal A, Bachert C, Bosnic-Anticevich $S$, et al. Allergic Rhinitis and its Impact on Asthma (ARIA) Guidelines-2016 revision. J Allergy Clin Immunol. 2017;140(4):950-8.

18. Dykewicz MS, Wallace DV, Baroody F, Bernstein J, Craig T, Finegold I, et al. Treatment of seasonal allergic rhinitis: an evidence-based focused 2017 guideline update. Ann Allergy Asthma Immunol. 2017;119(6):489-511.

19. Bousquet J, Devillier P, Arnavielhe S, Bedbrook A, Alexis-Alexandre $G$, van Eerd $\mathrm{M}$, et al. Treatment of allergic rhinitis using mobile technology with real-world data: The MASK observational pilot study. Allergy. 2018;73(9):1763-74

20. Gray WN, Netz M, McConville A, Fedele D, Wagoner ST, Schaefer MR. Medication adherence in pediatric asthma: a systematic review of the literature. Pediatr Pulmonol. 2018:53(5):668-84

21. Bousquet J, Murray R, Price D, Somekh D, Munter L, Phillips J, et al. The allergic allergist behaves like a patient. Ann Allergy Asthma Immunol. 2018;121(6):741-2.

22. Bedard A, Basagana X, Anto JM, Garcia-Aymerich J, Devillier P, Arnavielhe $S$, et al. Mobile technology offers novel insights on control and treatment of allergic rhinitis. The MASK study. J Allergy Clin Immunol. 2019;144(1):135-143.e6. https://doi.org/10.1016/j.jaci.2019.01.053.

23. Bateman ED, Reddel HK, O'Byrne PM, Barnes PJ, Zhong N, Keen C, et al. As-needed budesonide-formoterol versus maintenance budesonide in mild asthma. N Engl J Med. 2018;378(20):1877-87.

24. O'Byrne PM, FitzGerald JM, Bateman ED, Barnes PJ, Zhong N, Keen C, et al. Inhaled combined budesonide-formoterol as needed in mild asthma. N Engl J Med. 2018;378(20):1865-76.

25. Camargos P, Affonso A, Calazans G, Ramalho L, Ribeiro ML, Jentzsch N, et al. On-demand intermittent beclomethasone is effective for mild asthma in Brazil. Clin Transl Allergy. 2018;8:7.

26. Levine DMSS, Squires A, Nicholson J, Jay M. Technology-assisted weight loss interventions in primary care: a systematic review. J Gen Intern Med. 2015;30(1):107-17

27. Van der Roest HGWJ, Pastink C, Dröes RM, Orrell M. Assistive technology for memory support in dementia. Cochrane Database Syst Rev. 2017:6:CD009627. https://doi.org/10.1002/14651858.cd009627.

28. Bhattarai PPJ. The role of digital health technologies in management of pain in older people: an integrative review. Arch Gerontol Geriatr. 2017;68:14-24.

29. Hui CY, Walton R, McKinstry B, Jackson T, Parker R, Pinnock H. The use of mobile applications to support self-management for people with asthma: a systematic review of controlled studies to identify features associated with clinical effectiveness and adherence. J Am Med Inform Assoc. 2017;24(3):619-32.

30. Bousquet J, Hellings P, Agache I, Amat F, Annesi-Maesano I, Ansotegui I, et al. ARIA Phase 4 (2018): Change management in allergic rhinitis and asthma multimorbidity using mobile technology. J Allergy Clin Immunol 2018 (in press).

31. De Greve G, Hellings PW, Fokkens WJ, Pugin B, Steelant B, Seys SF. Endotype-driven treatment in chronic upper airway diseases. Clin Transl Allergy. 2017;7:22

32. Vandenplas O, Vinnikov D, Blanc PD, Agache I, Bachert C, Bewick M, et al. Impact of rhinitis on work productivity: a systematic review. J Allergy Clin Immunol Pract. 2018;6(4):1274-86.
33. Amaral R, Fonseca JA, Jacinto T, Pereira AM, Malinovschi A, Janson C, et al. Having concomitant asthma phenotypes is common and independently relates to poor lung function in NHANES 2007-2012. Clin Transl Allergy. 2018;8:13

34. Cingi C, Gevaert P, Mosges R, Rondon C, Hox V, Rudenko M, et al. Multi-morbidities of allergic rhinitis in adults: European Academy of Allergy and Clinical Immunology Task Force Report. Clin Transl Allergy. 2017;7:17.

35. Bousquet J, Van Cauwenberge P, Khaltaev N. Allergic rhinitis and its impact on asthma. J Allergy Clin Immunol. 2001;108(5 Suppl):S147-334.

36. Bousquet J, Khaltaev N, Cruz AA, Denburg J, Fokkens WJ, Togias A, et al. Allergic Rhinitis and its Impact on Asthma (ARIA) 2008 update (in collaboration with the World Health Organization, GA(2)LEN and AllerGen). Allergy. 2008;63(Suppl 86):8-160.

37. Bousquet J, Hellings PW, Agache I, Bedbrook A, Bachert C, Bergmann KC, et al. ARIA 2016: Care pathways implementing emerging technologies for predictive medicine in rhinitis and asthma across the life cycle. Clin Transl Allergy. 2016;6:47.

38. ARIA in the pharmacy: management of allergic rhinitis symptoms in the pharmacy. Allergic rhinitis and its impact on asthma. Allergy. 2004;59(4):373-87.

39. Carr WW, Yawn BP. Management of allergic rhinitis in the era of effective over-the-counter treatments. Postgrad Med. 2017;129(6):572-80.

40. Lombardi C, Musicco E, Rastrelli F, Bettoncelli G, Passalacqua G, Canonica GW. The patient with rhinitis in the pharmacy. A cross-sectional study in real life. Asthma Res Pract. 2015;1(1):4.

41. Fromer LM, Blaiss MS, Jacob-Nara JA, Long RM, Mannion KM, Lauersen LA. Current Allergic Rhinitis Experiences Survey (CARES): consumers' awareness, attitudes and practices. Allergy Asthma Proc. 2014;35(4):307-15.

42. Bousquet J, Neukirch F, Bousquet PJ, Gehano P, Klossek JM, Le Gal M, et al. Severity and impairment of allergic rhinitis in patients consulting in primary care. J Allergy Clin Immunol. 2006;117(1):158-62.

43. Bousquet J, Annesi-Maesano I, Carat F, Leger D, Rugina M, Pribil C, et al. Characteristics of intermittent and persistent allergic rhinitis: DREAMS study group. Clin Exp Allergy. 2005;35(6):728-32.

44. Bousquet PJ, Devillier P, Tadmouri A, Mesbah K, Demoly P, Bousquet J. Clinical relevance of cluster analysis in phenotyping allergic rhinitis in a real-life study. Int Arch Allergy Immunol. 2015;166(3):231-40.

45. del Cuvillo A, Montoro J, Bartra J, Valero A, Ferrer M, Jauregui I, et al. Validation of ARIA duration and severity classifications in Spanish allergic rhinitis patients - the ADRIAL cohort study. Rhinology. 2010;48(2):201-5.

46. Jauregui I, Davila I, Sastre J, Bartra J, del Cuvillo A, Ferrer M, et al. Validation of ARIA (Allergic Rhinitis and its Impact on Asthma) classification in a pediatric population: the PEDRIAL study. Pediatr Allergy Immunol. 2011;22(4):388-92.

47. Adams K, Greiner A, JM JC. The 1st Annual Crossing the Quality Chasm Summit—a Focus on Communities Chapter 5. 2004. https://www.ncbi. nlm.nih.gov/books/NBK215507.

48. Richard A, Shea K. Delineation of self-care and associated concepts. J Nurs Scholarsh. 2011:43:255-64.

49. Silva DD. Helping people help themselves: a review of the evidence considering whether it is worthwhile to support self-management. The Health Foundation 2011. http://www.healthorguk/sites/health/files/ HelpingPeopleHelpThemselvespdf. 2011.

50. Pearce G, Parke H, Pinnock H, Epiphaniou E, Bourne C, Sheikh A, et al. The PRISMS taxonomy of self-management support: derivation of a novel taxonomy and initial testing of utility. J Health Serv Res Policy. 2016:21:73-82.

51. Pinnock H, Effing T, Bourbeau J, van-der-Palen J. Self-management of respiratory disease. Respipedia, the respiratory wiki. 2017. http://respi pedia.ers-education.org/article/article/?idTopic $=217$. Accessed 29 Aug 2017.

52. Singh D, Ham C. A review of UK and international frameworks. http:// www.improvingchroniccareorg/downloads/review_of_internatio nal_framework.

53. Bodenheimer T, Lorig K, Holman H, Grumbach K. Patient self-management of chronic disease in primary care. JAMA. 2002;288(19):2469-75.

54. Hibbard J, Gillburt H. Supporting people to manage their health: an introduction to patient activation. King's Fund 2014. 2014. https://www. 
kingsfund.org.uk/sites/files/kf/field/field_publication_file/supporting -people-manage-health-patient-activation-may14.pdf.

55. Mosen D, Schmittdiel J, Hibbard J, Sobel D, Remmers G, Bellows J. Is patient activation associated with outcomes of care for adults with chronic conditions? J Ambul Care Manag. 2007;30:21-9.

56. Hellings PW, Borrelli D, Pietikainen S, Agache I, Akdis C, Bachert C, et al. European Summit on the Prevention and Self-Management of Chronic Respiratory Diseases: report of the European Union Parliament Summit (29 March 2017). Clin Transl Allergy. 2017;7:49.

57. Bousquet J, Anto JM, Annesi-Maesano I, Dedeu T, Dupas E, Pepin $J \mathrm{~L}$, et al. POLLAR: Impact of air POLLution on Asthma and Rhinitis; a European Institute of Innovation and Technology Health (EIT Health) project. Clin Transl Allergy. 2018;8:36.

58. Bousquet J, Chavannes NH, Guldemond N, Haahtela T, Hellings PW, Sheikh A. Realising the potential of mHealth to improve asthma and allergy care: how to shape the future. Eur Respir J. 2017. https://doi. org/10.1183/13993003.00447-2017.

59. Costa C, Menesatti P, Brighetti MA, Travaglini A, Rimatori V, Di Rienzo Businco A, et al. Pilot study on the short-term prediction of symptoms in children with hay fever monitored with e-Health technology. Eur Ann Allergy Clin Immunol. 2014;46(6):216-25.

60. Pizzulli A, Perna S, Florack J, Pizzulli A, Giordani P, Tripodi S, et al. The impact of telemonitoring on adherence to nasal corticosteroid treatment in children with seasonal allergic rhinoconjunctivitis. Clin Exp Allergy. 2014;44(10):1246-54.

61. Bianchi A, Tsilochristou O, Gabrielli F, Tripodi S, Matricardi PM. The smartphone: a novel diagnostic tool in pollen allergy? J Investig Allergol Clin Immunol. 2016;26(3):204-7.

62. Huang X, Matricardi PM. Allergy and Asthma Care in the Mobile Phone Era. Clin Rev Allergy Immunol. 2016.

63. Bastl K, Berger U, Kmenta M. Evaluation of pollen apps forecasts: the need for quality control in an eHealth service. J Med Internet Res. 2017;19(5):e152

64. Bousquet J, Arnavielhe S, Bedbrook A, Bewick M, Laune D, MathieuDupas E, et al. MASK 2017: ARIA digitally-enabled, integrated, personcentred care for rhinitis and asthma multimorbidity using real-worldevidence. Clin Transl Allergy. 2018;8:45

65. Samreth D, Arnavielhe S, Ingenrieth F, Bedbrook A, Onorato GL, Murray $\mathrm{R}$, et al. Geolocation with respect to personal privacy for the Allergy Diary app—a MASK study. World Allergy Organ J. 2018;11(1):15.

66. Recital 26-EU GDPR. EU general data protection regulation 2016/679. http://www.privacy-regulation.eu/en/recital-26-GDPR.htm. Accessed 18 Aug 2019

67. Article 4 EU GDPR. «Definitions ». EU general data protection regulation 2016/679 (GDPR). http://www.privacy-regulation.eu/en/article-4-defin itions-GDPR.htm. Accessed 18 Aug 2019

68. Sullivan PW, Nair KV, Patel BV. The effect of the Rx-to-OTC switch of loratadine and changes in prescription drug benefits on utilization and cost of therapy. Am J Manag Care. 2005;11(6):374-82.

69. Rachelefsky G, Farrar JR. Are you comfortable with over-the-counter intranasal steroids for children? A call to action. J Allergy Clin Immunol Pract. 2014;2(3):271-4.

70. Carney AS, Price DB, Smith PK, Harvey R, Kritikos V, Bosnic-Anticevich SZ, et al. Seasonal patterns of oral antihistamine and intranasal corticosteroid purchases from Australian community pharmacies: a retrospective observational study. Pragmat Obs Res. 2017;8:157-65.

71. OTC fluticasone furoate nasal spray (Flonase Sensimist) for allergic rhinitis. Med Lett Drugs Ther. 2017;59(1519):e70-e1.

72. Porteous T, Wyke S, Smith S, Bond C, Francis J, Lee AJ, et al. 'Help for Hay Fever', a goal-focused intervention for people with intermittent allergic rhinitis, delivered in Scottish community pharmacies: study protocol for a pilot cluster randomized controlled trial. Trials. 2013:14:217.

73. Walls RS, Heddle RJ, Tang ML, Basger BJ, Solley GO, Yeo GT. Optimising the management of allergic rhinitis: an Australian perspective. Med J Aust. 2005;182(1):28-33.

74. Smith L, Brown L, Saini B, Seeto C. Strategies for the management of intermittent allergic rhinitis: an Australian study. Health Expect. 2014:17(2):154-63.

75. O'Connor J, Seeto C, Saini B, Bosnic-Anticevich S, Krass I, Armour C, et al. Healthcare professional versus patient goal setting in intermittent allergic rhinitis. Patient Educ Couns. 2008;70(1):111-7.
76. Smith L, Nguyen T, Seeto C, Saini B, Brown L. The role of non-clinicians in a goal setting model for the management of allergic rhinitis in community pharmacy settings. Patient Educ Couns. 2011;85(2):e26-32.

77. Lourenco O, Calado S, Sa-Sousa A, Fonseca J. Evaluation of allergic rhinitis and asthma control in a Portuguese community pharmacy setting. J Manag Care Spec Pharm. 2014;20(5):513-22.

78. Kuipers $E$, Wensing $M$, de Smet $P$, Teichert $M$. Self-management research of asthma and good drug use (SMARAGD study): a pilot trial. Int J Clin Pharm. 2017:39(4):888-96.

79. Canonica GW, Triggiani M, Senna G. 360 degree perspective on allergic rhinitis management in Italy: a survey of GPs, pharmacists and patients. Clin Mol Allergy. 2015;13:25.

80. Smith P, Price D, Harvey R, Carney AS, Kritikos V, Bosnic-Anticevich $\mathrm{SZ}$, et al. Medication-related costs of rhinitis in Australia: a NostraData cross-sectional study of pharmacy purchases. J Asthma Allergy. 2017:10:153-61.

81. Brozek JL, AkI EA, Alonso-Coello P, Lang D, Jaeschke R, Williams JW, et al. Grading quality of evidence and strength of recommendations in clinical practice guidelines. Part 1 of 3 . An overview of the GRADE approach and grading quality of evidence about interventions. Allergy. 2009;64(5):669-77.

82. Brozek JL, Baena-Cagnani CE, Bonini S, Canonica GW, Rasi G, van Wijk RG, et al. Methodology for development of the Allergic Rhinitis and its Impact on Asthma guideline 2008 update. Allergy. 2008;63(1):38-46.

83. Padjas A, Kehar R, Aleem S, Mejza F, Bousquet J, Schunemann HJ, et al. Methodological rigor and reporting of clinical practice guidelines in patients with allergic rhinitis: QuGAR study. J Allergy Clin Immunol. 2014;133(3):777-83

84. Costa DJ, Amouyal M, Lambert P, Ryan D, Schunemann HJ, Daures JP, et al. How representative are clinical study patients with allergic rhinitis in primary care? J Allergy Clin Immunol. 2011:127(4):920-6.

85. Parmelli E, Amato L, Oxman AD, Alonso-Coello P, Brunetti M, Moberg $J$, et al. Grade evidence to decision (EtD) framework for coverage decisions. Int J Technol Assess Health Care. 2017;33(2):176-82.

86. Schunemann HJ, Mustafa R, Brozek J, Santesso N, Alonso-Coello P, Guyatt G, et al. GRADE Guidelines: 16. GRADE evidence to decision frameworks for tests in clinical practice and public health. J Clin Epidemiol. 2016;76:89-98.

87. Alonso-Coello P, Oxman AD, Moberg J, Brignardello-Petersen R, AkI EA, Davoli $M$, et al. GRADE Evidence to Decision (EtD) frameworks: a systematic and transparent approach to making well informed healthcare choices. 2: Clinical practice guidelines. BMJ. 2016;353:i2089.

88. Schunemann HJ, Hill SR, Kakad M, Vist GE, Bellamy R, Stockman L, et al. Transparent development of the $\mathrm{WHO}$ rapid advice guidelines. PLoS Med. 2007;4(5):e119.

89. Neumann I, Brignardello-Petersen R, Wiercioch W, Carrasco-Labra A, Cuello C, Akl E, et al. The GRADE evidence-to-decision framework: a report of its testing and application in 15 international guideline panels. Implement Sci. 2016;11:93.

90. update. BTSSIGNBGotMoAS. http://www.sign.ac.uk/sign-153-britishguideline-on-the-management-of-asthma.html. 2016.

91. Pinnock HEE, Pearce G, Parke HL, Greenhalgh T, Sheikh A, Griffiths CJ, Taylor SJC. Implementing supported self-management for asthma: a systematic review of implementation studies. BMC Med. 2015;13:127.

92. Bousquet J, Lund VJ, Van Cauwenberge P, Bremard-Oury C, Mounedji $\mathrm{N}$, Stevens MT, et al. Implementation of guidelines for seasonal allergic rhinitis: a randomized controlled trial. Allergy. 2003;58(8):733-41.

93. Bousquet J, Bodez T, Gehano P, Klossek JM, Liard F, Neukirch F, et al. Implementation of guidelines for allergic rhinitis in specialist practices. A randomized pragmatic controlled trial. Int Arch Allergy Immunol. 2009;150(1):75-82.

94. Bousquet J, Schünemann H, Togias A, Bachert C, Erhola M, Hellings $P$, et al. Next-generation ARIA guidelines for allergic rhinitis based on GRADE and real-world evidence. J Allergy Clin Immunol. 2019 (in press).

95. Bachert C, Bousquet J, Hellings P. Rapid onset of action and reduced nasal hyperreactivity: new targets in allergic rhinitis management. Clin Transl Allergy. 2018;8:25.

96. Bousquet J, Hellings PW, Agache I, Amat F, Annesi-Maesano I, Ansotegui IJ, et al. ARIA Phase 4 (2018): Change management in allergic rhinitis and asthma multimorbidity using mobile technology. J Allergy Clin Immunol. 2018. https://doi.org/10.1016/j.jaci.2018.08.049. 
97. Seys SF, Bousquet J, Bachert C, Fokkens WJ, Agache I, Bernal-Sprekelsen $M$, et al. mySinusitisCoach: patient empowerment in chronic rhinosinusitis using mobile technology. Rhinology. 2018;56(3):209-15.

98. Flandroy L, Poutahidis T, Berg G, Clarke G, Dao MC, Decaestecker E, et al. The impact of human activities and lifestyles on the interlinked microbiota and health of humans and of ecosystems. Sci Total Environ. 2018:627:1018-38.

99. Samolinski B, Fronczak A, Wlodarczyk A, Bousquet J. Council of the European Union conclusions on chronic respiratory diseases in children. Lancet. 2012;379(9822):e45-6.

100. Bousquet J, Tanasescu CC, Camuzat T, Anto JM, Blasi F, Neou A, et al. Impact of early diagnosis and control of chronic respiratory diseases on active and healthy ageing. A debate at the European Union Parliament. Allergy. 2013;68(5):555-61.

101. Bousquet J, Anto JM, Berkouk K, Gergen P, Antunes JP, Auge P, et al. Developmental determinants in non-communicable chronic diseases and ageing. Thorax. 2015;70(6):595-7.

102. Bousquet J, Addis A, Adcock I, Agache I, Agusti A, Alonso A, et al. Integrated care pathways for airway diseases (AIRWAYS-ICPS). Eur Respir J. 2014:44(2):304-23.

103. Bousquet J, Michel J, Standberg T, Crooks G, lakovidis I, Gomez M. The European Innovation Partnership on Active and Healthy Ageing: the European Geriatric Medicine introduces the EIP on AHA Column. Eur Geriatr Med. 2014;5(6):361-2.
104. Bousquet J, Dahl R, Khaltaev N. Global alliance against chronic respiratory diseases. Allergy. 2007;62(3):216-23.

105. Bousquet J, Barbara C, Bateman E, Bel E, Bewick M, Chavannes NH, et al. AIRWAYS-ICPs (European Innovation Partnership on Active and Healthy Ageing) from concept to implementation. Eur Respir J. 2016;47(4):1028-33

106. Muraro A, Fokkens WJ, Pietikainen S, Borrelli D, Agache I, Bousquet J, et al. European Symposium on Precision Medicine in Allergy and Airways Diseases: report of the European Union Parliament Symposium (October 14, 2015). Allergy. 2016;71(5):583-7.

107. Valiulis A, Bousquet J, Veryga A, Suprun U, Sergeenko D, Cebotari S, et al. Vilnius Declaration on chronic respiratory diseases: multisectoral care pathways embedding guided self-management, $\mathrm{mHealth}$ and air pollution in chronic respiratory diseases. Clin Transl Allergy. 2019;9:7.

\section{Publisher's Note}

Springer Nature remains neutral with regard to jurisdictional claims in published maps and institutional affiliations.
Ready to submit your research? Choose BMC and benefit from:

- fast, convenient online submission

- thorough peer review by experienced researchers in your field

- rapid publication on acceptance

- support for research data, including large and complex data types

- gold Open Access which fosters wider collaboration and increased citations

- maximum visibility for your research: over $100 \mathrm{M}$ website views per year

At $\mathrm{BMC}$, research is always in progress.

Learn more biomedcentral.com/submissions 